\title{
Electrical impedance spectroscopy (EIS) for biological analysis and food characterization: a review
}

\author{
Marco Grossi and Bruno Riccò \\ Department of Electrical Energy and Information Engineering "Guglielmo Marconi" (DEI), \\ University of Bologna, Bologna, Italy \\ Correspondence to: Marco Grossi (marco.grossi8@unibo.it)
}

Received: 9 March 2017 - Revised: 5 July 2017 - Accepted: 14 July 2017 - Published: 28 August 2017

\begin{abstract}
Electrical impedance spectroscopy (EIS), in which a sinusoidal test voltage or current is applied to the sample under test to measure its impedance over a suitable frequency range, is a powerful technique to investigate the electrical properties of a large variety of materials. In practice, the measured impedance spectra, usually fitted with an equivalent electrical model, represent an electrical fingerprint of the sample providing an insight into its properties and behavior. EIS is used in a broad range of applications as a quick and easily automated technique to characterize solid, liquid, semiliquid, organic as well as inorganic materials. This paper presents an updated review of EIS main implementations and applications.
\end{abstract}

\section{Introduction}

Electrical impedance spectroscopy (EIS) is a powerful technique (Barsoukov and Macdonald, 2005) that can be used in a broad range of applications, such as microbiological analysis (Ramirez et al., 2008), food products screening (Grossi et al., 2011a, 2014a), corrosion monitoring (Zhu et al., 2016), quality control of coatings (Amirudin and Thieny, 1995) and cement paste (Christensen et al., 1994), characterization of solid electrolytes (Rafiuddin, 2016) and human body analysis (Clemente et al., 2013).

EIS dates back to 1894 when W. Nerst measured the dielectric constant of aqueous electrolytes and other organic fluids (Nernst, 1894). However, it was only in the mid-1980s that the interest in EIS really grew substantially, thanks to computer-controlled digital instruments allowing quick and easy measurements as well as complex data processing and analysis. According to Orazem and Tribollet (Orazem and Tribollet, 2008), the number of scientific papers on EIS applications doubled every 4 or 5 years, with over 1200 papers published in 2006. A conference dedicated to EIS started in 1989 in Bombannes (France), and since then meetings have been held every 3 years.

EIS is essentially carried out as follows. In one of its two versions, the so-called "potentiostat EIS", a sine-wave volt- age,

$V(t)=\bar{V}+\hat{V} \cdot \sin (\omega t)$,

is applied to the sample under test (SUT) and the induced current,

$I(t)=\bar{I}+\hat{I} \cdot \sin (\omega t+\phi)$,

is measured. Then, the complex impedance is calculated as

$$
\begin{aligned}
Z(j \omega) & =\frac{V(j \omega)}{I(j \omega)}=\frac{\hat{V}}{\hat{I}} \cdot e^{-j \phi}=|Z| \cdot e^{j \cdot \operatorname{Arg}(Z)} \\
& =\operatorname{Re}(Z)+j \cdot \operatorname{Im}(Z)
\end{aligned}
$$

Here, $\hat{V}$ and $\hat{I}$ are the voltage and the current amplitude, respectively; $\bar{V}$ and $\bar{I}$ are the voltage and the current direct current (DC) values; $f$ is the test signal frequency; $\omega=2 \pi f$ the angular frequency; $\varphi$ the phase difference between $V(t)$ and $I(t) ; V(j \omega)$ and $I(j \omega)$ the Steinmetz transforms of $V(t)$ and $I(t)$, respectively. The sine-wave parameters can be calculated from the acquired signals using a fitting algorithm in the time domain (Grossi et al., 2012a) or by applying a fast Fourier transform algorithm (Yoo and Park, 2000).

In the other version of EIS, known as "galvanostat EIS", the SUT is stimulated with a sine-wave current and the 
(a)

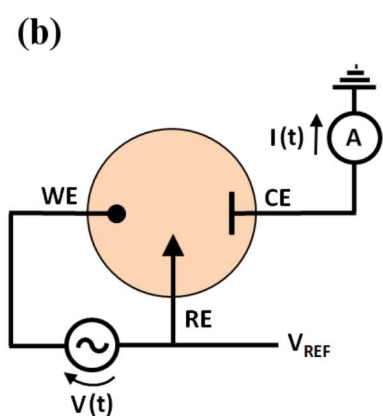

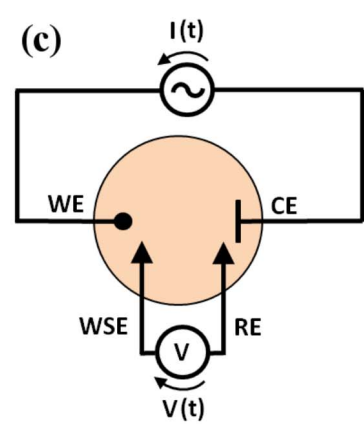

Figure 1. Measurement setup configurations used in EIS featuring (a) two electrodes, (b) three electrodes and (c) four electrodes.

voltage drop across the SUT is measured (of course, the impedance being still given by Eq. 3).

In most cases, the investigation by potentiostat EIS or galvanostat EIS is equivalent and provides the same results. There are, however, application-specific conditions making one technique more suitable than the other. For example, in the case of corrosion analysis with the open circuit voltage changing with time, galvanostat EIS assures the measurement is carried out at the true corrosion potential (Guyader et al., 2009).

EIS measurements can be made with a different number of electrodes in different configurations, among which the most common ones (usually called two-, three- and four-electrode implementations) are presented in Fig. 1.

In the simplest one, Fig. 1a, the stimulus is applied and the measurement is done using the same two electrodes, named the working electrode (WE) and the counter electrode (CE). In this case, of course, $Z(j \omega)$ includes contributions due to the sample interface at both electrodes.

To reduce the influence of such interfaces, a third electrode, called reference electrode (RE), can be added, as shown in Fig. 1b. In this case, usually used for electrochemical systems, the test signal is applied between the WE and the RE, while the current is measured at the CE. Since no current is drawn at the RE, the measured impedance includes only the contribution of the interface at the WE.

A further electrode can also be added, as shown in Fig. 1c, as it is often the case in galvanostat EIS. The sine-wave test current is applied between WE and CE, while the voltage is measured between the (added) working sensing electrode (WSE) and RE. Since no current is drawn at both WSE and RE, the measured impedance is independent of the electrode-sample interfaces.

In practice, the use of a higher number of electrodes makes the measurements more complex but also more precise; thus, a trade-off is in order with the optimum solution depending on the constraint of any specific application.

The impedance $Z(j \omega)$ is defined in the case of linear time invariant (LTI) systems, exhibiting three conditions: (a) linearity, (b) stability and (c) causality. However, since electrochemical systems exhibit a typically non-linear behavior, to avoid excessive perturbations to the SUT, small values of $\hat{V}$ (usually in the range 10 to $100 \mathrm{mV}$ ) are used to operate in a pseudo-linear region where $Z(j \omega)$ does not depend on $\hat{V}$.

The LTI conformity of the measured EIS data can be tested using the Kramers-Kronig (KK) relations (Boukamp, 1995):

$\operatorname{Im} Z(\omega)=\frac{2 \omega}{\pi} \int_{0}^{+\infty} \frac{\operatorname{Re} Z(x)-\operatorname{Re} Z(\omega)}{x^{2}-\omega^{2}} \mathrm{~d} x$

$\operatorname{Re} Z(\omega)=$

$\operatorname{Re} Z(+\infty)+\frac{2}{\pi} \int_{0}^{+\infty} \frac{x \cdot \operatorname{Im} Z(x)-\omega \cdot \operatorname{Im} Z(\omega)}{x^{2}-\omega^{2}} \mathrm{~d} x$

These equations can be used to calculate the KK residuals and test the data for linearity for increasing amplitudes of the stimulating signal (Lohmann et al., 2015; Haußmann and Melbert, 2017) in order to choose the best LTI-compliant signal-to-noise ratio. However, Eqs. (4) and (5) are not very useful since the integral must be calculated on the frequency range 0 to $+\infty$ while EIS data are available only on a limited frequency range. A practical implementation of the KK test has been proposed by Urquidi-Macdonald et al. (1990), where polynomial extrapolation was suggested outside the measured frequency range (Boukamp, 1995; Schönleber et al., 2014) where a chain of parallel RC elements is used to model impedance data.

While in most EIS applications the stimulating signal amplitude is kept low to work in the pseudo-linear region, in a limited number of cases the system non-linear response is investigated for additional information (Grossi et al., 2012b). A detailed review on such cases is discussed by Fasmin and Srinivasan (2017).

Since in the case of complex materials different components might exhibit different mobilities, $Z(j \omega)$ is generally measured over a wide range of frequencies. Usually, experimental data are represented with the Nyquist plot, where for each frequency, $\operatorname{Im}(Z)$ is plotted versus $\operatorname{Re}(Z)$. Since Nyquist plots mask the impedance dependance on frequency, sometimes the data are plotted using the Bode plots, where $|Z|$ and 
$\operatorname{Arg}(Z)$, or alternatively $\operatorname{Re}(Z)$ and $\operatorname{Im}(Z)$, are plotted versus $f$ (on a log scale).

The data are normally interpreted using equivalent circuits, made of resistors and capacitors, while more complex elements (such as constant phase elements or Warburg impedances) can also be added. Data fitting using these models and extraction of the circuit parameters is a computerassisted process carried out by specific software packages, such as multiple electrochemical impedance spectra parameterization (MEISP), EIS spectrum analyzer and Elchemea Analytical.

Most EIS investigations are carried out stimulating the SUT with a sequence of single-frequency sinusoidal test signals. This procedure results in high signal-to-noise ratio but leads to long measurement times that are sometimes unacceptable. This is, for instance, the case when very low frequencies (in the $\mathrm{mHz}$ or $\mu \mathrm{Hz}$ range) are used (such as for corrosion analysis and battery testing) or when the electrical parameters of the SUT change quickly (such as in the case of cardiovascular measurements). To achieve shorter measurement times, broad bandwidth test signals (with a spectral density covering the whole frequency range) are used coupled with discrete Fourier transform analysis. Such signals include, for example, multi-sine signals (Min et al., 2007; Breugelmans et al., 2010), rectangular pulses and Gaussian functions (Pliquett et al., 2000; Howie et al., 2001), sinc signals (Land et al., 2007; Lohmann et al., 2015; Haußann and Melbert, 2017) and chirp signals (Min et al., 2008).

In the past, when modern instruments were not available, EIS measurements were carried out by simultaneously displaying both test and response signals on a XY oscilloscope. For each tested frequency, the curve on the screen (Lissajous curve) was analyzed to extract the electrical parameters. The main drawback of this technique, now obsolete, was the very long measurement time (often in the range of many hours) incompatible with use on non-stationary systems.

Today, most EIS investigations are carried out using dedicated lab instruments (frequency response analyzers and LCR meters) featuring high accuracy, a wide range of test frequencies, the possibility to make measurements with a two-, three- or four-electrode configuration in both potentiostat and galvanostat operation mode. Moreover, these instruments normally feature proprietary software for data analysis. However, they are expensive (usually many thousands of US dollars) and must be used in a lab environment. Thus, they are not suitable for online measurements in the field.

Since the early 1980s, with the diffusion of low-cost microcontrollers, the possibility to design portable electronic systems aimed at EIS measurements has become a reality. In these systems, the excitation signal is usually generated by means of digital-to-analog converters (DACs), while the waveforms are acquired with analog-to-digital converters (ADCs). Dzwonczyk et al. (1992) used an electronic system (featuring the Intel 80C196 microcontroller, eight 10-bit ADC channels and an RS-232 port), to measure the myocardial impedance spectrum (Dzwonczyk et al., 1992). Later, Atmanand et al. presented a portable LCR meter based on the Intel 8751 microcontroller (Atmanand et al., 1995; Atmanand and Kumar, 1996). Yang et al. (2006) designed a portable device for bioimpedance spectroscopy measurements, based on the microcontroller PIC18F452 by Microchip and using the integrated circuit AD9833 to generate the test signal, capable of measuring impedances from $9 \Omega$ to $5.7 \mathrm{k} \Omega$ in the frequency range $20 \mathrm{kHz}$ to $1 \mathrm{MHz}$. In 2007 , Bogonez and Riu proposed a bioimpedance system, based on microcontroller PIC18F2420 by Microchip, to measure the impedance of kidneys (from $0.07 \Omega$ to $1.4 \mathrm{k} \Omega$ ) in the frequency range $200 \mathrm{~Hz}$ to $2 \mathrm{MHz}$ (Bogonez and Riu, 2007). An ad hoc designed board (featuring an ARM STM32 microcontroller) that can perform EIS measurements in the frequency range $1 \mathrm{mHz}$ to $100 \mathrm{kHz}$ and measure impedances from $1 \Omega$ to $10 \mathrm{M} \Omega$ was presented by Piasecki et al. (2016).

Recently, the design of embedded portable systems for EIS measurements has become even simpler with the introduction on the market of the integrated circuit AD5933 by Analog Devices, a low-cost impedance analyzer system on chip. This device, featuring an on-board test voltage generator (maximum frequency $100 \mathrm{kHz}$ ) and a 12-bit 1 MSPS $\mathrm{ADC}$ for signals acquisition, can measure impedances in the range $1 \mathrm{k} \Omega-10 \mathrm{M} \Omega$ (extendable to $100 \Omega-10 \mathrm{M} \Omega$ with an additional circuit). The AD5933 can be used to realize handheld, battery-operated impedance analyzers, thanks to its $\mathrm{I}^{2} \mathrm{C}$ interface allowing quick and easy communication with a microcontroller. Although much less accurate than expensive benchtop instruments, the AD5933 is adequate for many EIS applications.

For instance, Simic (2013) presented an impedance analyzer based on the microcontroller ATMega128 and AD5933 (with impedance and frequency range $1 \mathrm{k} \Omega$ to $5 \mathrm{M} \Omega$ and 1 to $100 \mathrm{kHz}$, respectively), LCD display and micro SD card for data filing; Breniuc et al. (2014) used a DS1077 external oscillator to generate frequencies lower than $1 \mathrm{kHz}$; Hoja and Lentka (2009) proposed the use of two AD5933 devices for a portable impedance analyzer with extended range of impedances $(100 \Omega$ to $10 \mathrm{G} \Omega$ ) and frequencies $(0.01 \mathrm{~Hz}$ to $100 \mathrm{kHz}$ ); Alonso-Arce et al. (2013) presented a in-body sensor node for bio-monitoring powered with a $50 \mathrm{~mA}$ coin-cell battery and capable of providing a 20-month lifetime; Margo et al. (2013) extended the use of AD5933 to four-electrode measurements. Other authors proposed the use of AD5933 to make low-cost biosensor systems for applications in DNA and protein sensing (van Grinsven et al., 2010), detection of bladder cancer (Chuang et al., 2016) and avian flu virus (Wang et al., 2015). Kamat et al. (2014) discussed a sensor for non-invasive blood glucose analysis; Ferreira et al. proposed an application for total body composition (Ferreira et al., 2010) and body fluid distribution analysis (Ferreira et al., 2011); Park et al. (2006) discussed the implementation of a sensor system to monitor civil infrastructures (particularly for loosening bolts in a bolt-jointed structure and detection 
(a)
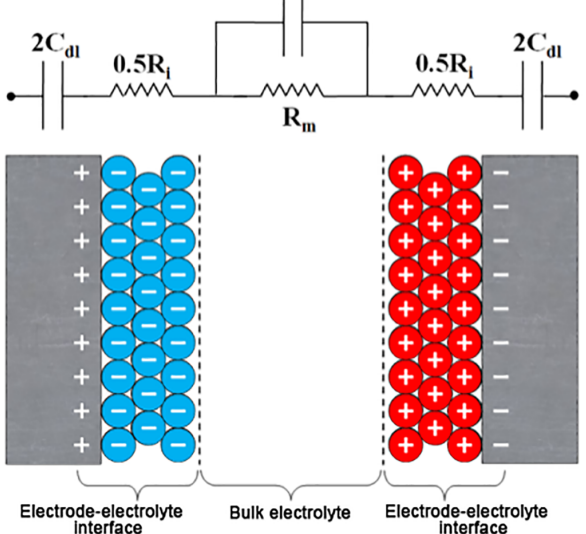

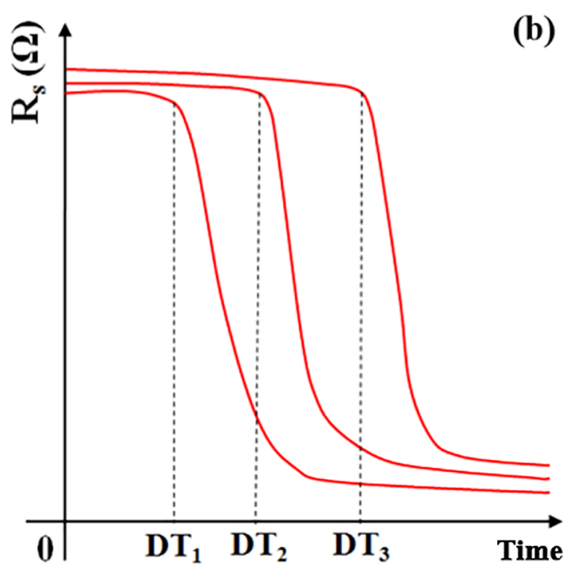

Figure 2. (a) Equivalent electrical circuit for two electrodes immersed in liquid electrolyte; (b) measured electrical resistance versus time during bacterial growth.

of corrosion in an aluminum beam); Durante et al. (2016) developed a sensor to be used for real-time monitoring to detect fraud in milk composition.

To review a vast field of applications, the rest of this paper is organized as follows: Sect. 2 is dedicated to microbial concentration measurement; EIS applications aimed at human body analysis are discussed in Sect. 3; Sect. 4 reviews the methods for electrical characterization of food products and assessment of food quality. Finally, other non-biological EIS applications are presented in Sect. 5.

\section{Detection of microorganisms}

Microbiological screening is important in different fields, from medical to environmental monitoring, from food safety to military applications (Alocilja and Radke, 2003), since excessive bacterial concentrations or the presence of particular dangerous pathogens (such as Escherichia coli O157:H7 or Salmonella Typhimurium) can seriously endanger human health. It is estimated that, only in the US, food pathogens are responsible for 76 million illnesses, 325000 hospitalizations and 5000 deaths every year (Mead et al., 2000).

The standard reference for bacterial concentration measurement is the plate count technique (PCT) (Kaspar and Tartera, 1990), which is reliable and accurate but essentially a laboratory technique (hence not suitable for in situ and online measurements) with long response time (from 24 to $72 \mathrm{~h}$ ).

From this point of view, EIS offers interesting and viable alternatives.

\subsection{Impedance microbiology}

The detection of microorganisms by means of electrical measurements dates back to 1898 , when Stewart discovered that the increase of bacterial populations changed the electrical conductivity in the growth medium (Stewart, 1899). How- ever, it was only in the late 1970s, thanks to the works of Fistenberg-Eden and Eden (Fistenberg-Eden and Eden, 1984; Fistenberg-Eden, 1983), Ur and Brown (1975) and Cady (1978), that the technique, known as impedance microbiology (IM), showed its full potential.

IM exploits the fact that bacterial metabolism transforms uncharged or weakly charged compounds in highly charged ones, thus producing a change in the electrical characteristics of the growth medium from which the bacterial concentration responsible for the phenomenon can be worked out.

For this purpose, measurements are usually done at a single frequency using a couple of electrodes made of inert material (stainless steel or platinum) in direct contact with the electrolyte where microbial growth takes place. The equivalent circuit model for such a system is shown in Fig. 2a, where $C_{\mathrm{m}}$ and $R_{\mathrm{m}}$ are the medium capacitance and resistance, respectively; $R_{\mathrm{i}}$ is the resistance of the electrodeelectrolyte interface and $C_{\mathrm{dl}}$ is the capacitance of a double layer formed at such an interface. Since this double layer is only few Ångströms thick, $C_{\mathrm{dl}}$ is large (typically in the range of $\mu \mathrm{F}$ ), while $C_{\mathrm{m}}$ is usually in the picofarad ( $\mathrm{pF}$ ) range. Thus, at frequencies lower than about $1 \mathrm{MHz}$ (as it is normally the case in IM), $C_{\mathrm{m}}$ can be neglected and the system can be modeled as the series of a resistance $R_{\mathrm{S}}=R_{\mathrm{m}}+R_{\mathrm{i}}$ and a capacitance $C_{\mathrm{dl}}$.

IM works as follows: the SUT, if necessary, diluted in an enriching medium, is stored at a temperature favoring bacterial growth. Then, the electrical parameters $\left(R_{\mathrm{S}}\right.$ and $\left.C_{\mathrm{dl}}\right)$ are measured at time intervals of a few minutes. Until the microbial concentration $\left(C_{\mathrm{B}}\right)$ is lower than a critical threshold $\left(C_{\mathrm{th}}\right.$ in the order of $\left.10^{6}-10^{7} \mathrm{CFU} \mathrm{mL}{ }^{-1}\right)$, the electrical parameters are almost constant at their baseline values, while they exhibit significant variations when $C_{\mathrm{B}}>C_{\mathrm{th}}$. The time needed for the electrical parameters to deviate from the baseline values, called detect time (DT), is lower for highly contaminated samples and higher for samples featuring low 
contamination. For example, as shown in Fig. 2b, considering three samples with decreasing values of $C_{\mathrm{B}}$ from 1 to 3 , it is $\mathrm{DT}_{1}<\mathrm{DT}_{2}<\mathrm{DT}_{3}$. Furthermore, since DT is a linear function of the logarithm of the initial bacterial concentration (Grossi et al., 2009), $C_{\mathrm{B}}$ can be estimated from the measured DT once the system has been calibrated for the particular combination of sample type and bacterial strains.

IM has been used to measure bacterial concentration in different kind of samples, with the correct choice of incubation temperature and enriching medium playing a key role to achieve a good accuracy. Grossi et al. (2008) showed that the total bacterial concentration in ice cream samples can be measured with good accuracy (compared with the PCT) and without any enriching medium at $T=39^{\circ} \mathrm{C}$, provided the system is suitably calibrated for products of different composition. The same authors obtained good results with samples of raw milk (Grossi et al., 2011b) (correlation $R^{2}=0.728$ at $T=18^{\circ} \mathrm{C}$ ); beer (Pompei et al., 2012), where the lactobacilli concentration was measured at $T=35^{\circ} \mathrm{C}$ by diluting the sample in $3 \%$ yeast extract; and brackish waters (Mancuso et al., 2016).

Hardy et al. (1977) discussed the application of IM to frozen vegetables, showing how a microbial concentration of $10^{5} \mathrm{CFU} \mathrm{mL}{ }^{-1}$ can be detected with a response time of 5 h. Settu et al. (2015) showed the feasibility to detect Escherichia coli in human urine samples without any dilution in enriching media, using a test frequency of $10 \mathrm{~Hz}$ and achieving a good correlation $\left(R^{2}=0.90\right)$ with the PCT. Johnson et al. (2014) tested different food products and various bacterial strains using indirect IM (monitoring the concentration of $\mathrm{CO}_{2}$ produced by the bacteria) with a commercial instrument (RABIT by Don Whitley Scientific) and found a good correlation $\left(R^{2}>0.84\right)$ for $80 \%$ of the tested products (Johnson et al., 2014).

IM was also used to test the antimicrobial efficiency of different antibiotics and chemical preservatives (Zhou and King, 1995; Silley and Forsythe, 1996). In this case, samples inoculated with the same concentration of the bacterial strain under test but different concentrations of antibiotic are used, and the measured DT is plotted versus the antibiotic concentration (more effective antibiotics leading to higher DTs).

Recently, research in IM was mainly aimed at reducing instrument dimensions (to allow automatic and in situ measurements) and improving measurement performance (in particular, lowering the response time). Grossi et al. (2010, 2013a, 2017) designed a portable biosensor to measure bacterial concentration in liquid and semiliquid media that includes an incubation chamber (featuring stainless steel electrodes, heating resistances and a temperature sensor for thermoregulation) and two electronic boards, connected to a PC via RS232 for data analysis and filing. A Telit GT 863-PY module integrated into the system allows wireless data transmission to remote hosts.

Uria et al. (2016) used a platinum interdigitated electrode array for IM with milk samples spiked with concentrations of Escherichia coli ranging from $10^{2}$ to $10^{6} \mathrm{CFU} \mathrm{mL}^{-1}$. In this case, a novel calibration technique was used where the electrical parameters were monitored only at two time intervals (270 and 390 min from the start of the assay) at a test frequency of $10 \mathrm{kHz}$. The authors claimed slightly better performances than standard IM systems for lower bacterial concentrations $\left(10^{2} \mathrm{CFU} \mathrm{mL}{ }^{-1}\right)$, though not in the case of highly contaminated samples.

Choi et al. (2009) proposed the use of a solid culture medium for IM. In this case, two thick acrylic plate electrodes were used with a $15 \mathrm{~mm} \times 15 \mathrm{~mm} \times 5 \mathrm{~mm}$ solid medium while the inoculated sample was dropped on the medium surface and allowed to diffuse. The obtained results showed that, compared with those based on liquid media, the proposed biosensor had comparable performance in spite of its simpler fabrication and portability. Puttaswamy and Sengupta produced a capillary microchannel with gold-coated electrodes (Puttaswamy and Sengupta, 2010) that, thanks to the increased electrolyte resistance, was able to monitor the medium capacitance $C_{\mathrm{m}}$ with a multi-frequency approach $(1 \mathrm{kHz}$ to $1 \mathrm{MHz})$ allowing a drastic reduction in response time (4 times faster than traditional IM systems on the market). A microfluidic biochip was presented by GomezSjoberg et al. (2005) that uses dielectrophoresis (DEP) to separate bacterial cells from the supporting electrolyte and trap them inside a small chamber $(400 \mathrm{pL})$ by DEP forces. In this way, bacteria can be concentrated (by a factor of $10^{4}$ to $10^{5}$ ), thus allowing much faster detection.

\subsection{Impedance biosensors}

In IM, the selectivity towards particular bacterial species is achieved by diluting the SUT in selective enriching media (such as MacConkey Broth for coliforms and Mannitol Salt Broth for staphylococci). In the case of specific pathogenic strains, such as Escherichia coli O157:H7 or Salmonella Typhimurium, that can be dangerous even in very small concentrations, a different approach is used: a particular bioreceptor that is able to bind with the target bacterial strain is immobilized on the electrode and the resulting binding modifies the system electrical parameters. Compared with IM, impedance biosensors are usually characterized by higher selectivity, higher sensitivity and shorter response times, and the implementation by microfluidic strategies can result in even better performances. Nevertheless, some limitations exist, mainly related to the stability of the immobilized bioreceptor, and its implementation is more complex than IM.

The typical experimental setup used in impedance biosensors (electrochemical cells) is a three-electrode configuration, where the test signal is applied between WE and $\mathrm{RE}$, while the current is measured at CE. The electrolyte in which the three electrodes are immersed is usually a phosphate-buffered saline (PBS) solution with the presence of $\left[\mathrm{Fe}(\mathrm{CN})_{6}\right]^{3-/ 4-}$ used as redox probe. The $\mathrm{CE}$ is usually realized with a platinum wire while a $\mathrm{Ag} / \mathrm{AgCl}$ or saturated 
(a)
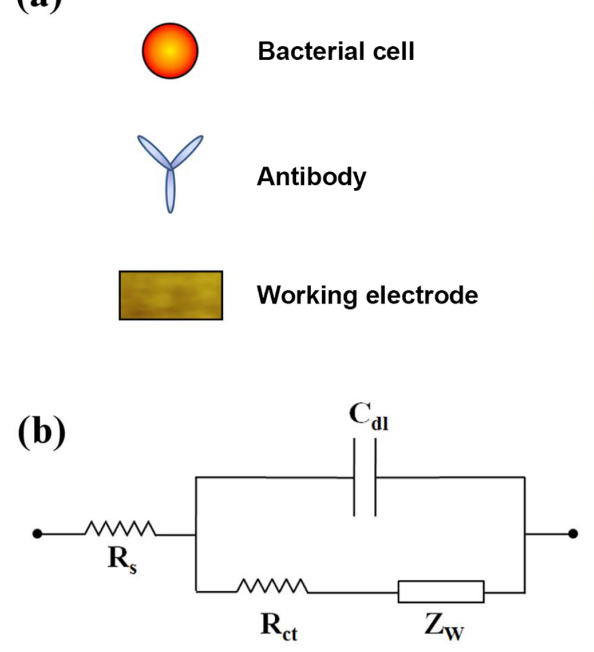
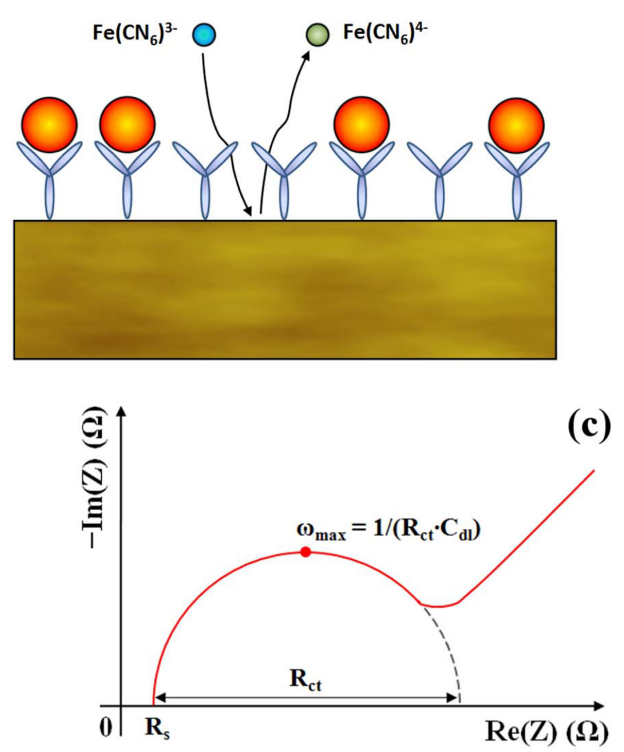

Figure 3. (a) Modified working electrode with immobilized bioreceptor; (b) equivalent electrical circuit of the biosensor; (c) Nyquist plot of the equivalent circuit.

calomel electrode is used as RE. The WE, instead, is modified immobilizing the bioreceptor on its surface, whose general structure is shown in Fig. 3a. The most common bioreceptor for bacteria detection is an antibody (in this case, the term "immunosensor" is often used); however, other options have recently been presented, such as nucleic acids, bacteriophages and lectins (Wang et al., 2012). When the target bacteria bind to the bioreceptor, the redox reaction of $\left[\mathrm{Fe}(\mathrm{CN})_{6}\right]^{3-/ 4-}$ with the $\mathrm{WE}$ is hindered and the electrochemical cell impedance changes. As discussed in Barreiros dos Santos et al. (2009), the immobilization technique has a great impact on the biosensor performance.

The impedance of the three-electrode electrochemical cell is usually modeled with the equivalent circuit shown in Fig. 3b, where $R_{\mathrm{S}}$ is the electrical resistance of the electrolyte; $C_{\mathrm{dl}}$ the double-layer capacitance at the WEelectrolyte interface; $R_{\mathrm{ct}}$ the charge transfer resistance due to the redox reaction of $\left[\mathrm{Fe}(\mathrm{CN})_{6}\right]^{3-/ 4-}$ with the $\mathrm{WE}$ and $Z_{\mathrm{W}}$ the Warburg impedance due to the diffusion process of reactants (Randviir and Banks, 2013; Chang and Park, 2010).

Sometimes, $C_{\mathrm{dl}}$ is modeled with a constant phase element (CPE) for better accuracy, and the impedance of CPE can then be expressed as

$Z_{\mathrm{CPE}}(j \omega)=\frac{1}{Q \cdot(j \omega)^{\alpha}}=\frac{\cos \left(\frac{\alpha \pi}{2}\right)}{Q \cdot \omega^{\alpha}}-j \frac{\sin \left(\frac{\alpha \pi}{2}\right)}{Q \cdot \omega^{\alpha}}$,

where $Q$ represents the double-layer capacitance, while the parameter $\alpha$ accounts for the non-ideal electrode-electrolyte interface (the case $\alpha=1$ refers to an ideal capacitance).
The Warburg impedance, in the ideal case of a diffusion layer with infinite thickness, can be expressed as

$Z_{\mathrm{W}}(j \omega)=\frac{\sigma}{\sqrt{\omega}} \cdot(1-j)$,

where $\sigma$ is the Warburg coefficient.

The electrical circuit of Fig. $3 b$ is described using the Nyquist plot of Fig. 3c. For low values of test frequency, the dominant effect is ion diffusion (Warburg impedance) and the plot is essentially a straight line with slope $45^{\circ}$. At high frequencies instead, where diffusion time constant is much longer than the signal period, the plot is described by a semicircle with diameter given by the charge transfer resistance $R_{\text {ct. }}$. This parameter is the most used one to estimate bacterial concentration, since, when bacterial cells bind to the target bioreceptors at the WE surface, the redox reaction is hindered and $R_{\mathrm{ct}}$ increases. Sometimes, however, the double layer capacitance $C_{\mathrm{dl}}$ is used instead.

Many impedance biosensors have been presented in the last few years to measure the concentration of different pathogens. Yang et al. (2004) proposed an interdigitated array (IDA) microelectrode capable of detecting Escherichia coli $\mathrm{O} 157: \mathrm{H} 7$ in the concentration range $4.36 \times 10^{5}-4.36 \times$ $10^{8} \mathrm{CFU} \mathrm{mL}^{-1}$. In this case, E. coli antibodies were immobilized on the microelectrode surface by physical absorption and, when exposed to E. coli concentration from $10^{5}$ to $10^{8} \mathrm{CFU} \mathrm{mL}^{-1}, R_{\mathrm{ct}}$ increased from $750 \Omega$ to about $2 \mathrm{k} \Omega$. An immunosensor for the same bacterial strain was developed by Li et al. (2011), which used a gold electrode coated on both sides with a $8 \mathrm{MHz}$ quartz crystal on which $E$. coli antibodies were immobilized through a self-assembled monolayer (SAM). Differently from other biosensors, here the $E$. 
coli concentration was estimated from the $C_{\mathrm{dl}}$ shift, $1 \mathrm{~h}$ after the bacteria were placed on the electrode. The detection limit in E. coli pure culture was $10^{2} \mathrm{CFU} \mathrm{mL}^{-1}$ and a linear response was found from $10^{2}$ to $10^{5} \mathrm{CFU} \mathrm{mL}^{-1}$. The immunosensor was successfully tested also on real food samples (milk, spinach and ground beef) but the detection limit was found to be higher than in the case of $E$. coli culture $\left(10^{3} \mathrm{CFU} \mathrm{mL}{ }^{-1}\right.$ for milk and spinach and $10^{4} \mathrm{CFU} \mathrm{mL}^{-1}$ for ground beef).

Radke and Alocilja proposed a microfabricated biosensor (featuring interdigitated gold microelectrodes with immobilized bacteria antibodies) capable of measuring $E$. coli $\mathrm{K} 12$ concentrations in the range $10^{5}$ to $10^{7} \mathrm{CFU} \mathrm{mL}-1$ with response time of $5 \mathrm{~min}$ (Radke and Alocilja, 2004). Dong et al. (2013) discussed a label-free impedance immunosensor for the detection of Salmonella Typhimurium developed by immobilizing Salmonella antibodies on gold nanoparticles and poly (amidoamine)-multi-walled carbon nanotubes - chitosan nanocomposite film modified glassy carbon electrode. This biosensor, able to measure concentrations from $10^{3}$ to $10^{7} \mathrm{CFU} \mathrm{mL}{ }^{-1}$ in pure culture, was successfully tested also with real milk samples. An impedance immunosensor for detection of Salmonella Typhimurium was proposed by Dastider et al. (2015) which is based on a microfluidic, highly interdigitated electrode array with immobilized Salmonella antibodies. The lower detection limit of this biosensor was $3 \times 10^{3} \mathrm{CFU} \mathrm{mL}^{-1}$ and it was demonstrated that the microfluidic approach allows lower detection limit and faster response time.

Recently, other bioreceptors have been tested such as nucleic acids, bacteriophages and lectins (Wang et al., 2012). Bacteriophages, in particular, are viruses that recognize and bind to specific receptors on the target bacteria. When they come in contact with the target bacteria, they infect the cell by viral DNA injection that, in about 30-60 min, leads to bacterial cell lyses. Thus, $R_{\mathrm{ct}}$ variation due to bacteriophages binding to the host bacteria is somewhat different from other bioreceptors in that at the beginning $R_{\mathrm{ct}}$ increases due to bacterial binding hindering the redox reaction at the WE surface, while later it decreases due to cell lyses allowing the release of cell ionic material. Bacteriophages have been used as immobilizing bioreceptors in biosensors for different bacterial species (Shabani et al., 2008; Gervais et al., 2007; Tolba et al., 2012), as well as for an unconventional approach to IM where bacteriophages are integrated into the culture broth, and the monitored variation of electrolyte resistance is mainly due to conductivity increase induced by cell lyses (and not only due to bacterial metabolism) (Mortari et al., 2015). According to the authors, this approach results in much better performances with a detection limit of $1 \mathrm{CFU} \mathrm{mL} \mathrm{m}^{-1}$ or lower and response time less than $1 \mathrm{~h}$.

\section{Analysis of human body composition}

EIS is widely used as a quick, non-invasive and low-cost technique to estimate human body composition and, in this particular application, it is often referred to as bioelectrical impedance analysis (BIA).

The human body can be divided into different compartments, as shown in Fig. 4a (Kyle et al., 2004; Mialich et al., 2014). Fat-free mass (FFM) (sometimes referred as lean body mass) includes all body parts that are not fat mass (FM). FFM, in turn, can be divided into various components: bone mineral (about $7 \%$ ); extracellular water (ECW, about $29 \%$ ); intracellular water (ICW, about $44 \%$ ); and visceral protein. Total body water (TBW) represents the sum of ECW and ICW.

Fat tissues are characterized by low electrical conductivity (i.e., high impedance values) while lean tissues present high electrical conductivity (i.e., low impedance values) due to the high content of electrolytes (Kanti Bera, 2014). TBW is the major compound of FFM that helps the flow of electrical current due to the conductivity of electrolytes dissolved in body water (Khalil et al., 2014).

BIA is often used to estimated TBW and also FFM, since for healthy people in a normal hydration state TBW is about $73.2 \%$ of FFM.

BIA normally features a four-electrode configuration in galvanostat mode: a sinusoidal test current is applied between WE and CE and the corresponding voltage drop is measured between WSE and RE. The most common configuration used to this purpose (referred to as hand-to-foot configuration) is shown in Fig. 4b: one driving electrode and one sensing electrode are placed on the right hand of the subject under test, while the other two electrodes are applied to the right foot. However, other electrode configurations have also been used, such as hand-to-hand (Deurenberg and Deurenberg-Yap, 2002; Ghosh et al., 1997) and foot-tofoot (Xie et al., 1999; Utter et al., 1999) configurations.

In BIA, the impedance is also influenced by the test frequency. ICW is surrounded by cell membrane that is essentially an insulator; thus, it does not contribute to the impedance at low frequency, where the electrical current flows essentially within the ECW. However, at high frequency, the current can penetrate the cell membrane; hence, the overall impedance is due to both ICW and ECW. Figure $4 \mathrm{c}$ presents an equivalent electrical circuit of the whole human body. The current path through ICW can be modeled as the series of a capacitance due to cell membrane $\left(C_{\text {cell }}\right)$ and a resistance due to ICW electrolytes $\left(R_{\mathrm{ICW}}\right)$, all in parallel with a resistance due to $\mathrm{ECW}$ electrolytes $\left(R_{\mathrm{ECW}}\right)$. At low frequency, the body impedance is essentially resistive due to ECW, while at higher frequencies the reactive component due to $C_{\text {cell }}$ is not negligible.

Different BIA techniques have been used that use different frequencies. 
(a)

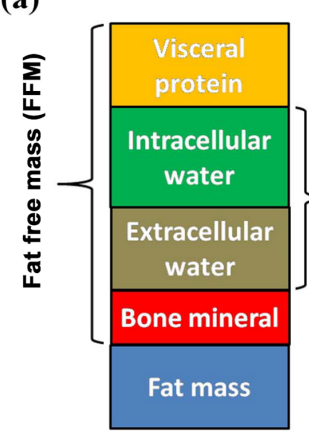

(b)

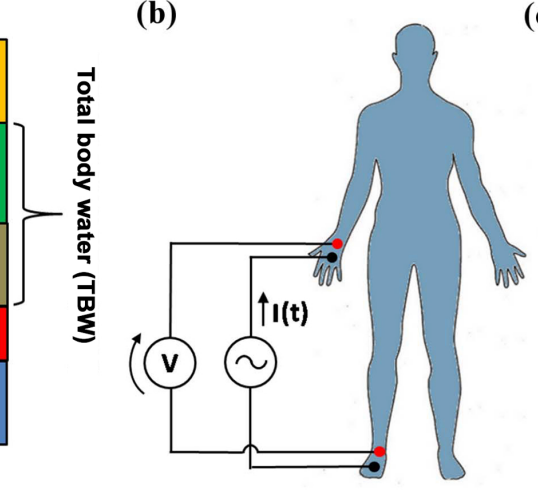

(c)

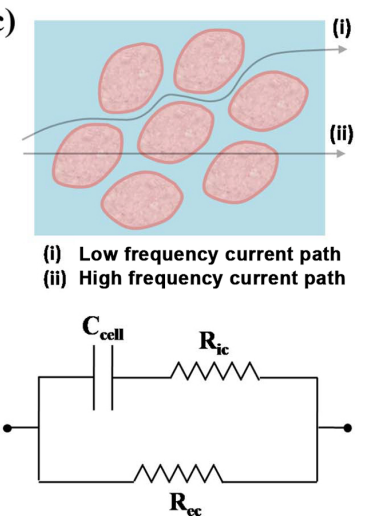

Figure 4. (a) The different compartments of the human body; (b) a typical four-electrode configuration for BIA measurements; (c) equivalent electrical circuit used to interpret measured data in BIA.

The simplest, and the first to be introduced, is singlefrequency BIA (SF-BIA), where the body impedance, as well as its resistive and reactive components, is measured at a single frequency, usually $50 \mathrm{kHz}$, with the measured impedance being due to a mix of contributions of ICW and ECW. SFBIA has been widely used to estimate TBW and FFM. Because of the use of a single frequency, however, it is not able to reliably estimate the ECW / ICW ratio. In SF-BIA, the body parameter (usually TBW or FFM) is estimated using empirical linear equations, depending on the characteristics of the subject under test (height, weight, etc.). Many commercial systems exist that estimate TBW and FFM using SFBIA where the body parameters are automatically estimated by means of empirical equations stored in the system memory together with personal physical data.

In multi-frequency BIA (MF-BIA), the ECW / ICW ratio can also be estimated, in addition to TBW and FFM, using empirical linear equations. According to Hannan et al. (1994), however, MF-BIA is characterized by poor reproducibility for frequencies lower than $5 \mathrm{kHz}$ and higher than $200 \mathrm{kHz}$.

In bioelectrical impedance spectroscopy (BIS), the impedance is measured over a wide range of frequencies and the data are used to best fit the equivalent circuit of Fig. $4 \mathrm{c}$ to calculate the resistance at zero and infinite frequency $\left(R_{0}\right.$ and $R_{\infty}$, respectively). These parameters are then used in the equations proposed by Hanai (1968) to predict different body compartments parameters.

The strongest point of BIA is the possibility to replace invasive and lengthy laboratory analysis with a quick, noninvasive test that can be carried out in a medical office. However, BIA is also characterized by restrictions and limitations, such as lack of accuracy and reproducibility for particular groups of subjects (pregnant women, people wearing a pacemaker, subjects with skin lesions and altered fluid balance); need for the tested subject to follow strict procedures before the test (no alcohol for at least $8 \mathrm{~h}$, no food and no drinking water for at least $4 \mathrm{~h}$ ); and the need for periodic maintenance of both instrumentation and electrodes (Mialich et al., 2014).

One of the first investigations on the prediction of TBW content using SF-BIA was carried out by Hoffer (1969). In this case, the whole human body was modeled from an electrical point of view as a cylinder of height $H$ and base area $A$. Denoting with $\rho$ the constant electrical resistivity (accounting for the body conducting electrolytes) and considering the impedance to be purely resistive, it is

$R=\rho \cdot \frac{H}{A}=\rho \cdot \frac{H \cdot H}{A \cdot H}$.

Since $A \cdot H$ is the volume of the conductor $(V)$, it is

$V=\rho \cdot \frac{H^{2}}{R}$.

Thus, the volume of conducting electrolytes is proportional to the ratio between the squared height and the measured impedance (in practice coinciding with its resistive component).

The investigation on 34 patients showed a good correlation coefficient (0.92) between TBW and $H^{2} /|Z|$, where the impedance modulus was measured at $100 \mathrm{kHz}$.

Since then, a large number of equations to predict FFM and TBW using SF-BIA have been proposed. In addition to the ratio of Eq. (9), many other parameters have been added to the equation for better accuracy, such as weight, age, gender and ethnicity of the subject. For example, Kyle et al. (2011) proposed a single equation to predict FFM in subjects from 22 to 94 years old as function of resistance and reactance measured at $50 \mathrm{kHz}$, height, weight and gender. Such equation was tested in 343 healthy subjects and achieved a correlation coefficient of 0.986 .

The posture of the subject during measurement is also important. Rush et al. (2006) compared the measured impedance at $50 \mathrm{kHz}$ in 205 subjects in two different positions: standing and lying. The results showed that the 
measured impedance was slightly higher in the lying position. The same experiment was carried out by Kagawa et al. (2014) that measured bioelectrical parameters in boys and adult males using both SF-BIA and MF-BIA: in this case, the impedance at $50 \mathrm{kHz}$ was found higher in the lying position in boys but no significant differences were found in adult males. The conclusion was that the posture is influential in the estimation of the ECW / ICW ratio but not as far as TBW is concerned.

In general, SF-BIA is capable of estimating FFM and TBW with good accuracy in healthy subjects. However, it becomes inaccurate when applied to people with diseases or alterations in body fluid compartments. For example, Haverkort et al. (2015) estimated FFM and TBW in surgical and oncological patients using equations developed for healthy subjects and the accuracy was significantly worse than in the case of healthy subjects. Gudivaka et al. (1999) compared the results from SF-BIA at $50 \mathrm{kHz}$ and MF-BIA (5 to $500 \mathrm{kHz}$ ) in subjects with altered body water compartmentalization due to infusion with lactated Ringer solution and/or a diuretic agent concluding that MF-BIA performs better under conditions of altered hydration. Jaffrin and Morel (2008) compared the results obtained with SF-BIA and BIS in the estimation of TBW and ECW finding that BIS is equivalent to SF-BIA in the estimation of TBW in healthy subjects, but it performs better in patients with abnormal fluid distribution or with a large amount of adipose tissue. Ibrahim et al. (2005) analyzed 184 patients affected by Dengue hemorrhagic fever using SF-BIA at $50 \mathrm{kHz}$ and found that the reactance measured at $50 \mathrm{kHz}$ can be used in classifying the patient risk category.

A more recent approach is segmental BIA (SEG-BIA), where the human body is modeled composed of five different segments (the two arms, the trunk and the two legs). By means of multi-electrode configurations placed in different parts of the body, impedance measurements of the different segments can be made and local fluid distribution can be estimated. Using an eight-electrode SEG-BIA with three different frequencies $(5,50$ and $250 \mathrm{kHz})$, Shafer et al. (2009) analyzed 132 adults exhibiting a large range of body mass indexes (normal, overweight and obese) and found that body fat percent $(\mathrm{BF} \%)$ can be accurately estimated in subjects classified as normal and overweight, while a significant overestimation was found in subjects classified as obese. Eight electrodes around the abdominal surface were used with SFBIA at $50 \mathrm{kHz}$ by Yoneda et al. (2007) to estimate the visceral fat volume. Chinen et al. (2015) presented a new measurement method featuring six electrodes (two hands, two armpits and two feet) and working on a wide range of frequencies (from $20 \mathrm{~Hz}$ to $1 \mathrm{MHz}$ ) as well as a new equivalent electrical circuit to interpret the measured data. According to these authors the system can accurately measure the impedance value of the human trunk (characterized by lower impedance values than arms and legs).
Local BIA measurements have been also used to characterize the muscular tissue (Clemente et al., 2014). In 2014, Clemente et al. realized a measurement system featuring BIS (from 1 to $60 \mathrm{kHz}$ ) with four electrodes placed on the subject arms. The electrical model used to describe the system was the same as that of Fig. 4c, except that the capacitance membrane was modeled with a CPE. The investigations showed that, when the muscle is contracted, the extracellular resistance $\left(R_{\mathrm{ec}}\right)$ presents a very significant increment (probably due to the impediment to blood flow caused by the contraction).

\section{Assessment of food quality parameters}

A large number of EIS applications have been proposed to characterize and screen different food products for quality assessment.

\subsection{Fruits}

In the case of fruits, EIS has been widely used to estimate the ripening state as well as to detect defects (such as fruit bruising). As a first approximation, the (complex) structure of fruits and vegetables can be modeled with the simplified structure of Fig. 5a (proposed by Labavitch et al., 1998) where the plant cells are all surrounded by the extracellular cell wall and delimited by a phospholipid bilayer membrane (plasmalemma). Inside the plasmalemma, the nucleus is immersed in a viscous fluid (cytoplasm). The inner boundary of the cytoplasm is marked by a membrane (tonoplast) that stores the vacuole (Hall et al., 1974). From an electrical point of view, different electrical models have been proposed to describe the plant response to the passage of electric current. One of the simplest is the Cole model, described by the same circuit of Fig. 4c, where $R_{\mathrm{ec}}$ represents the resistance of the extracellular cell wall, $R_{\text {ic }}$ the cytoplasm resistance and $C_{\text {cell }}$ the membrane capacitance. A slightly more complex model, proposed by Hayden et al. (1969), is shown in Fig. 5b, where $R_{1}$ represents the cell wall resistance, $R_{2}$ the resistance of the cell membrane, $R_{3}$ the cytoplasm resistance and $C$ the capacitance of all membranes. A more detailed model (doubleshell model), proposed by Zhang and Willison (1991), is represented in Fig. 5c, where $R_{1}$ represents the cell wall resistance, $R_{2}$ the cytoplasm resistance, $R_{3}$ the vacuole resistance, $C_{1}$ the plasmalemma capacitance and $C_{2}$ the tonoplast capacitance. An even more complex model was proposed by Zhang et al. (1990) but it is rarely used. Moreover, some authors simply measure the product impedance modulus at a single or multiple frequencies, while others use empirical models using networks of resistances and distributed elements.

Many papers on the use of EIS to characterize the physiological state of fruits were published in the 1990s by Harker and co-workers. Harker and Maindonald (1994) presented the results of the study on the correlation between change of impedance and ripening of nectarines. The fruits (culti- 
(a)

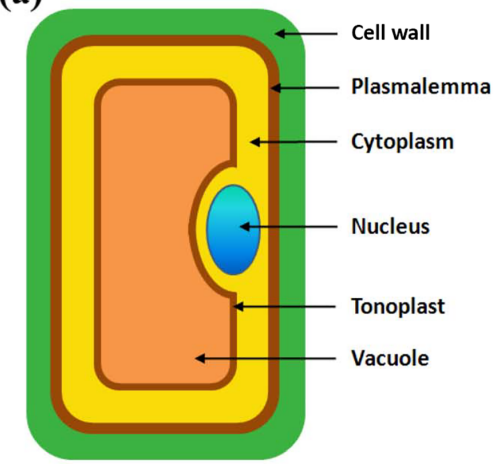

(b)

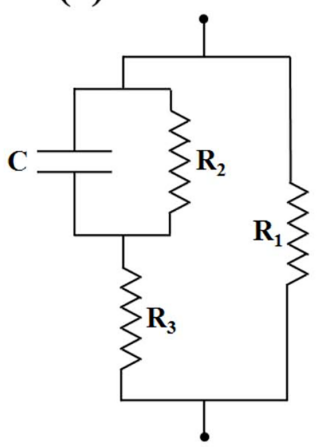

(c)

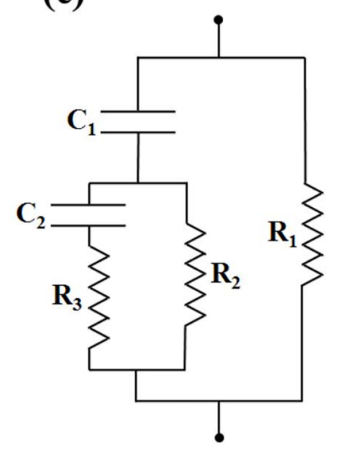

Figure 5. (a) Model of the anatomical structure of a fruit; (b) Hayden equivalent electrical circuit; (c) double-shell equivalent electrical circuit.

var Fantasia) were peeled and the (removed) tissue was implanted with a linear array of five silver electrodes in radial position (inter-electrode distances of 10,20 and $30 \mathrm{~mm}$ ). The samples were characterized at frequencies ranging from $50 \mathrm{~Hz}$ to $1 \mathrm{MHz}$. The data were represented in the Nyquist plot as a semicircle and fitted with the double-shell model of Fig. 5c. The measured resistance at low frequency $(50 \mathrm{~Hz})$ significantly decreased with the ripening process at $20^{\circ} \mathrm{C}$ while small variations were observed in the membrane capacitance and negligible ones in the high-frequency resistance $(300 \mathrm{kHz})$, thus indicating that the electrical changes were mainly due to the fruit cell wall (extracellular). To test how the chilling injury induced by cool storage affects the fruit electrical parameters during ripening, a set of fruits was stored at $0^{\circ} \mathrm{C}$ for several weeks and then monitored during the ripening process at $20^{\circ} \mathrm{C}$ : this resulted in a much more limited variation of the resistance measured at $50 \mathrm{~Hz}$ during the ripening process.

Harker and Forbes (1997) published the results of a similar experiment carried out on persimmons (cultivar Fuyu) using the same experimental setup. In this case too, only the resistance at low frequency $(50 \mathrm{~Hz})$ was influenced by the ripening process at $20^{\circ} \mathrm{C}$, but the resistance at $50 \mathrm{~Hz}$ increased in the first 21 days and then decreased until day 35 (at the end of the ripening reaching a value lower than at day 0 ). When stored at $7{ }^{\circ} \mathrm{C}$ for several weeks to induce chilling injuries, only negligible variations were monitored during the successive ripening at $20^{\circ} \mathrm{C}$.

In 2000, Bauchot, Harker and Arnold investigated the impedance changes of kiwis (cultivar Hayward) during the ripening process at $20^{\circ} \mathrm{C}$ under the same frequency range (50 Hz to $1 \mathrm{MHz}$ ) (Bauchot et al., 2000). In this case, different electrode configurations were tested but no significant variation in the measured impedance was observed (both at low and high frequency). Jackson and Harker (2000) presented a study on apple bruise detection by impedance measurements. Apples (cultivars Granny Smith and Splendour) were measured by a couple of $\mathrm{Ag} / \mathrm{AgCl}$ electrodes implanted into the fruit at distance of $35 \mathrm{~mm}$ from one another and to a depth of $3 \mathrm{~mm}$. Signal frequencies ranging from $50 \mathrm{~Hz}$ to $1 \mathrm{MHz}$ were used before and after falls from different heights to induce injury. The results showed that the measured resistance at $50 \mathrm{~Hz}$ decreased after bruising and the changes were correlated ( $R^{2}$ from 0.36 to 0.72 ) to the induced bruise weight.

The results of Harker and co-workers are important since they provide information on the relationship between the physiological state of different fruits and changes in their electrical parameters. This technique, however, cannot be used for online quality control in industrial or commercial environments since it uses electrodes implanted into the fruit tissue.

For this reason, more recently, several authors monitored electrical parameters in fruits using non-destructive techniques. Rehman et al. (2011) designed a system with two spring-loaded cylindrical electrodes (with diameter of $5 \mathrm{~mm}$ ) capable of impedance measurements on intact fruits with skin. A balance was installed in the bottom of the measuring system and a temperature sensor based on the AD590 IC was used for temperature compensation. The system was tested by monitoring the impedance changes of mangoes during the ripening process in the frequency range 1 to $200 \mathrm{kHz}$ using an electrical model composed of a resistance and a capacitance in parallel. The effective resistance showed higher variations at low frequency $(1 \mathrm{kHz})$ with an increase in the first phase of the ripening process, reaching a maximum after 5 days and then decreasing with further ripening.

Juansah et al. (2012) presented a system for nondestructive impedance measurements on Garut citrus fruits where the sample was placed between two conducting plates and monitored in the frequency range $50 \mathrm{~Hz}$ to $1 \mathrm{MHz}$. The measured data were interpreted using a new electrical model and reasonable correlation with fruit firmness and acidity was found.

Finally, non-destructive impedance measurements using surface electrodes were used by Vozary and Benko (2010) 

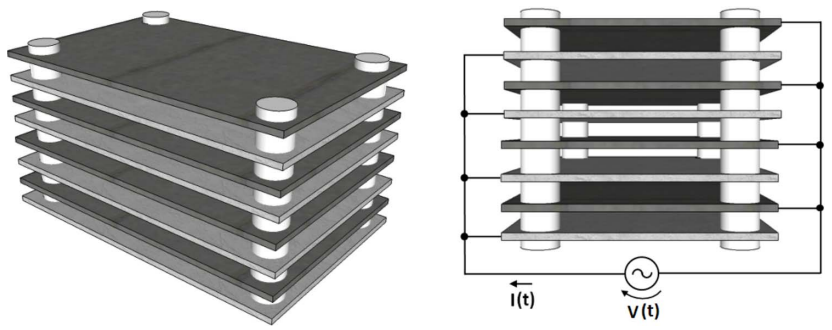

Figure 6. Parallel plate capacitive sensor used to investigate the properties of vegetable oils.

on apples and by Chowdhury et al. on bananas (2017a) and mandarin oranges (2017b).

\subsection{Vegetable oils}

In the case of vegetable oils, for frequencies lower than $1 \mathrm{MHz}$, the system composed of a couple of electrodes immersed in the sample can be modeled as a simple capacitance, since edible oils are good insulators (their electrical conductivity at low frequency can be as low as $0.5 \mathrm{nS} \mathrm{m}^{-1}$ ) (Prevc et al., 2013).

Lizhi et al. (2008) characterized 10 different vegetable oils in the frequency range $100 \mathrm{~Hz}-1 \mathrm{MHz}$. The most useful parameter was found to be the relative dielectric constant $\varepsilon_{\mathrm{r}}$ (that can be estimated by measuring the electrical capacitance). $\varepsilon_{\mathrm{r}}$ depends on the oil's fatty acid composition and moisture content and decreases for increasing temperature. As for frequency, it is relatively constant in the range $100 \mathrm{~Hz}-500 \mathrm{kHz}$ while it decreases with frequency from $500 \mathrm{kHz}$ to $1 \mathrm{MHz}$. Capacitive measurements on edible oil are usually carried out using sensors such as the one shown in Fig. 6, where multiple parallel plate capacitors are connected in parallel so as to maximize the capacitance and increase the signal-to-noise ratio. Denoting with $A$ the electrode area, $h$ the inter-electrode distance, $\varepsilon_{0}$ the vacuum dielectric constant $\left(8.85 \times 10^{-12} \mathrm{C}^{2} N^{-1} \mathrm{~m}^{-2}\right), N$ the number of capacitor in parallel and neglecting fringing field effects, the sensor capacitance $C_{\text {sensor }}$ can be expressed as

$C_{\text {sensor }}=N \cdot \varepsilon_{0} \cdot \varepsilon_{\mathrm{r}} \cdot \frac{A}{h}$.

A capacitive sensor has been used by Stevan Jr. et al. (2015) to monitor the degradation of vegetable oils subjected to thermal stress. When used for frying with repeated thermal cycles at high temperatures, oils are subject to alterations in their structure with degradation of organoleptic properties and potential danger for consumers' health. For this purpose, the possibility to monitor oil degradation by capacitive measurements has been successfully proven. In particular, soybean oil samples have been submitted to two different tests: (1) a constant thermal stress at $180^{\circ} \mathrm{C}$ for $8 \mathrm{~h}$; (2) 18 heating cycles between 20 and $250^{\circ} \mathrm{C}$. In both cases, an increase of $\varepsilon_{\mathrm{r}}$ with the number of cycles and progressive oil degradation evaluated by reference methods has been found. The use of capacitive measurements to assess the degradation of frying oil has also been investigated by Yang et al. (2016). In this case, soybean oil has been subjected to heath stress tests $(6 \mathrm{~h}$ for five consecutive days) at $180-190{ }^{\circ} \mathrm{C}$ in the presence and absence of fried dough with different moisture levels $(0,20$, 40 and $60 \%$ ). The dielectric parameters have been measured in the frequency range $40 \mathrm{~Hz}-100 \mathrm{MHz}$ and the results indicated that $\varepsilon_{\mathrm{r}}$, its variation between low and high frequency as well as the loss factor, all increase with frying time and are useful parameters to estimate oil degradation with frying time and conditions (higher moisture of the dough accelerates oil degradation).

Capacitive measurements to estimate $\varepsilon_{\mathrm{r}}$ have been used by Ragni et al. (2013) to determine the water content in extra virgin olive oils. Because of the large difference in relative dielectric constant between water and edible oils (77 versus 3) capacitive measurements are able to detect water even in very small quantity (178 to $1321 \mathrm{mg} \mathrm{kg}^{-1}$ of oil). For this purpose, six different frequencies have been tested $(500 \mathrm{~Hz}$, $2,8,32,128$ and $512 \mathrm{kHz}$ ) and the best results have been obtained at $8 \mathrm{kHz}$, with $R^{2}=0.962$ for samples artificially created from a single oil sample by adding different concentrations of water, while $R^{2}=0.818$ for real olive oil samples featuring different composition in terms of fatty acids.

The possibility to detect the adulteration of extra virgin olive oil with low-quality vegetable oils by measuring $\varepsilon_{\mathrm{r}}$ has been investigated by Lizhi et al. (2010). Olive oil samples were artificially adulterated by spiking the SUT with vegetable oils belonging to the linoleic and low-content linolenic acid type (sesame, canola, soybean and corn) as well as to oleic acid type (safflower). The samples were investigated in the frequency range $100 \mathrm{~Hz}-1 \mathrm{MHz}$ using techniques of multivariate data analysis, such as principal component analysis (PCA) and partial least squares (PLS) regression. The results showed that the adulteration with vegetable oils belonging to the linoleic and low-content linolenic acid type can be detected, while in the case of oleic acid adulterants the differences are probably too small for a reliable discrimination.

A different approach was used by Grossi et al. (2014a) to measure the acidity of olive oil samples (Valli et al., 2016). In this case, the SUT was mixed with an hydroalcoholic solution (60\% ethanol, $40 \%$ distilled water) to create an emulsion. The sensor used for conductivity measurement, with frequency ranging from $20 \mathrm{~Hz}$ to $2 \mathrm{MHz}$, was a $50 \mathrm{~mL}$ vial featuring a couple of stainless steel electrodes. An electrical model consisting of a conductance $G_{\mathrm{m}}$ (accounting for the emulsion electrical conductivity) and a capacitance $C_{\mathrm{m}}$ (taking into account the dielectric properties) was used. As shown in Fig. 7, when the free fatty acids of the oil come in contact with the hydroalcoholic reagent, a dissociation occurs, releasing ions that increase $G_{\mathrm{m}}$. In the experiments, 55 olive oil samples with free acidity in the range $0.2-2.3 \%$ were tested and a good correlation $\left(R^{2}=0.9308\right)$ was found with the acidity values obtained with the reference titration 


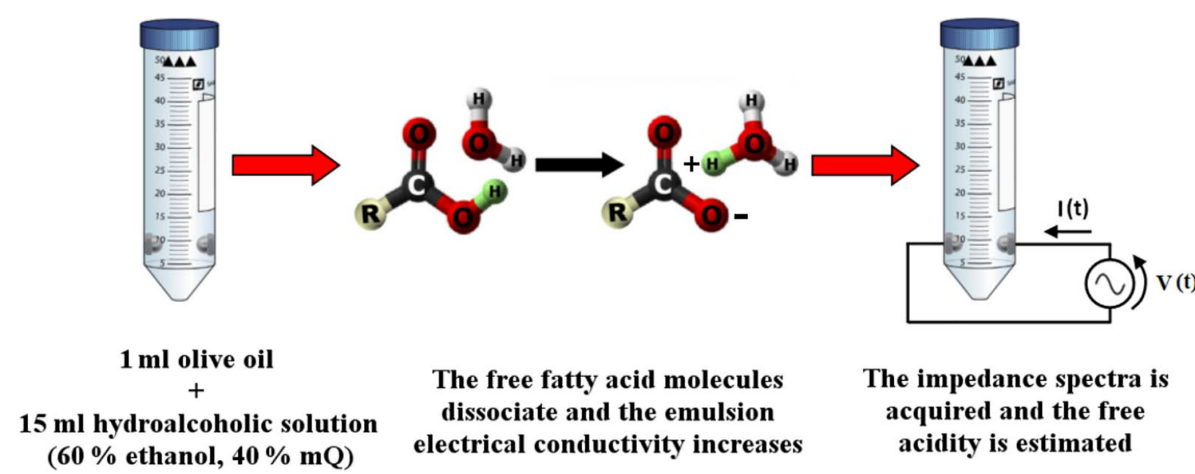

Figure 7. Procedure to estimate the free acidity in olive oil using the technique discussed in Grossi et al. (2014a).

method. This technique was also implemented in the form of a portable electronic system suitable for in situ measurements in oil mills and packaging centers (Grossi et al., 2013b, 2014b).

The electrical characterization of an emulsion created with the oil sample and a suitable chemical reagent was also used by Yang et al. (2014) to measure the peroxide value in olive oil samples.

\subsection{Dairy products}

EIS has been widely used to characterize different dairy products. Mabrook and Petty (2003) investigated the relationship between milk composition and electrical conductivity. Different cow milk samples (full fat, skimmed, semiskimmed and lactose reduced) were investigated with a couple of gold electrodes $(15 \mathrm{~mm} \times 6 \mathrm{~mm}, 1 \mathrm{~mm}$ apart $)$ in the frequency range $5 \mathrm{~Hz}-1 \mathrm{MHz}$ at $8^{\circ} \mathrm{C}$, stimulating the sample with a sine-wave voltage of $V_{\mathrm{RMS}}=700 \mathrm{mV}$. The results indicated that the milk electrical conductivity provides interesting information at high frequency $(100 \mathrm{kHz})$, where the electrode polarization is negligible and the milk conductance is affected by both salt and fat content (increasing and decreasing the conductivity, respectively), while the lactose does not have significant effects.

In 2006, the same authors used the same experimental setup to detect cow milk adulteration with added water (in the concentration 0 to $8 \%$ ) (Mabrook et al., 2006). The results have shown that milk conductance varies with added water, but the variation is highly dependent on the type of milk: with skimmed milk the conductivity decreases monotonically with increasing water content, while in the case of full fat milk it presents a local minimum and with creamy milk it has two local maxima.

A deeper investigation on the use of EIS to detect bovine milk adulteration was carried out by Durante et al. (2016) considering different types of adulterants: drinking water, de-ionized water, hydrogen peroxide, sodium hydroxide and formaldehyde $37 \%$ as well as mixes of these adulterants. Measurements were carried out using an impedance probe built with two stainless steel rods spaced $10 \mathrm{~mm}$ and immersed for $20 \mathrm{~mm}$ in the sample. The obtained data were analyzed with a k-nearest neighbors algorithm and discrimination between adulterated and non-adulterated samples was achieved with $94.9 \%$ correct answers.

Ferrero et al. (2014) built an electronic system for early detection of mastitis in cows. The system, based on the microcontroller PIC16F876 (Microchip Technology), performed measurements of electrical conductivity at $10 \mathrm{kHz}$ using two stainless steel electrodes $10 \mathrm{~mm}$ apart and with effective area of about $100 \mathrm{~mm}^{2}$. A temperature sensor (LM35) was integrated to compensate for conductivity variations due to temperature. The detection of mastitis was realized analyzing the milk electrical conductivity as well as its variations during the milking time.

Grossi et al. (2012b) characterized ice cream using EIS to cluster the samples according to their composition. A total of 21 ice cream samples belonging to three different groups (creamy milk based, frozen yogurt and fruit based) were characterized in the frequency range $20 \mathrm{~Hz}-10 \mathrm{kHz}$ using stainless steel electrodes with two different configurations: the samples were electrically characterized both in the linear and non-linear region. The investigation of the non-linear response provided further information allowing reliable discrimination between milk-based and fruitbased products, while further discrimination between creamy mixes and frozen yogurt required measuring the sample $\mathrm{pH}$. The same authors proposed a technique, based on EIS, to control ice cream freezing and determine the freezing endpoint (Grossi et al., 2011a). The front grid of an industrial batch freezer (Coldelite Compacta Top 3002 RTX) was modified to feature two stainless steel electrodes for the electrical characterization during the freezing process: measurements of $|Z|$ and $\operatorname{Arg}(Z)$ were carried out at time intervals of $1 \mathrm{~min}$ in the frequency range $20 \mathrm{~Hz}-10 \mathrm{kHz}$ with a test signal of $100 \mathrm{mV}$. The best results were achieved at low frequency $(20 \mathrm{~Hz})$ with good correlation between measured impedance and current drawn by the dasher motor (the latter being the reference technique to assess the freezing status of ice cream mixes). 

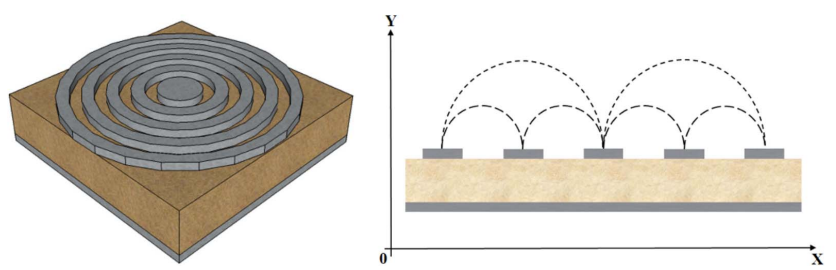

Figure 8. Fringing electric field (FEF) sensor used for spatial imaging of the moisture present in the sample under test.

EIS was used by Kitamura et al. (2000) for online monitoring of yogurt processing. Yogurt was produced at different fermentation temperatures between 30 and $42^{\circ} \mathrm{C}$, and electrical measurements were carried out at time intervals of $10 \mathrm{~min}$ using two platinum plates $(20 \times 20 \mathrm{~mm}, 10 \mathrm{~mm}$ apart $)$ in the frequency range $50 \mathrm{~Hz}-100 \mathrm{kHz}$. The parameter best suited to monitor the fermentation process was found to be the ratio $\left(Z_{\text {RATIO }}\right)$ between the impedances measured at $100 \mathrm{kHz}$ and at $100 \mathrm{~Hz}$. Curves of $Z_{\text {RATIO }}$ presented a bending point corresponding to the start of coagulation and a good correlation ( $R^{2}$ higher than 0.9 ) between $Z_{\mathrm{RATIO}}$ and sample acidity as well as hardness were found.

\subsection{Other food products}

Moisture is an important parameter in a variety of food products, and EIS can be used to make quick and non-destructive measurements of such a parameter. Particularly interesting is the use of fringing electric field (FEF) sensors that can measure the average moisture and make spatial imaging of the investigated sample ( $\mathrm{Li}$ et al., 2006). An example of the FEF sensor is shown in Fig. 8: a set of concentric electrodes is realized on one side of an insulating substrate, while on the other side guard rings are used to shield the sensing electrodes from noise. A current test signal is injected between a couple of electrodes and the resulting voltage is measured to calculate the impedance. Since the penetration depth of the electric field is proportional to the distance between coplanar electrodes, electrodes at different distances make it possible to measure in different points of the sample. The main drawback of such a technique is that the measured impedance increases with electrode distance and this can lead to inaccuracies when highly spaced electrodes are involved. FEF sensors are also used in parallel plate configuration, with one in front of the other and the SUT between them.

$\mathrm{Li}$ et al. (2003) used FEF sensors in this configuration to monitor the moisture content in cookies. In this case, sensors with three concentric electrodes were used with frequency ranging between $10 \mathrm{~Hz}$ and $10 \mathrm{kHz}$. Samples with moisture between 0.2 and $1 \mathrm{~g}$ were tested and the best results were achieved at high frequency $(10 \mathrm{kHz})$ : the agreement between the moisture estimated with the proposed method and that obtained with the reference technique was very good at high moisture level ( $2 \%$ error) but it was much worse in the lower moisture range (35\% error). Bhatt and Nagaraju $(2008,2009)$ used a FEF sensor featuring five ring electrodes to measure moisture in bread: measurements were carried out every $24 \mathrm{~h}$ for 5 days using a driving current of $1 \mathrm{~mA}$ in the frequency range $50 \mathrm{~Hz}-100 \mathrm{kHz}$. The best correlation with moisture was found looking at the impedance modulus calculated at the frequency where $\operatorname{Re}(Z)=\operatorname{Im}(Z)$. The spatial imaging capability of FEF sensors allowed to estimate moisture both in the bread crust and crumb, showing that the former features higher values for both moisture and measured impedance than the latter.

Yang et al. (2013) measured moisture in pork meat with an experimental setup (very similar to that of BIA) featuring four stainless steel needle electrodes ( $1 \mathrm{~cm}$ apart) inserted in the meat sample and measurements carried out at $20^{\circ} \mathrm{C}$ in the frequency range $1-250 \mathrm{kHz}$. A total of 44 samples were tested ( 30 for modeling and 14 for validation) and a good correlation was found between the measured impedance at high frequency and moisture $\left(R^{2}=0.802\right.$ for the modeling set and $R^{2}=0.879$ for the validation set). Both moisture and lipid content were determined in pork meat samples by Chanet et al. (1999). In this case, 72 samples were investigated using two stainless steel electrodes in the frequency range $5 \mathrm{kHz}-$ $2 \mathrm{MHz}$ and two different approaches were tested: (1) moisture and lipid content were estimated using the whole spectrum and a PLS algorithm to build a model; (2) the parameters were estimated with single-frequency measurements at $275 \mathrm{kHz}$. In both cases, a good correlation between the estimated parameters and their value obtained with a reference techniques was found, with the PLS approach resulting only in slightly better accuracy than single-frequency measurements.

Soltani et al. (2014) determined the moisture content of different oilseeds (sesame, soybean, canola) using EIS with a capacitive cylindrical sensor achieving a good correlation using hyperbolic regression lines with a coefficient of determination higher than 0.9.

EIS has also been used for fish quality assessment. Niu and Lee (2000) used a three-electrode system (WE and CE made of platinum, while $\mathrm{RE}$ was a $\mathrm{Ag} / \mathrm{AgCl}$ electrode) with frequency between $0.1 \mathrm{~Hz}$ and $100 \mathrm{kHz}$ to determine the freshness of different types of fish (carp, sea bass and herring). The phase angle and the imaginary component of the measured admittance have been found to be the best parameters suited for the purpose. The frequency providing the best sensitivity varied with the fish type, but in all cases four different states corresponding to different fish aging could be reliably discriminated.

Fuentes et al. (2013) investigated the use of EIS to discriminate fresh and frozen-thawed fish. A total of 30 fish samples (sea breams) were investigated at $20^{\circ} \mathrm{C}$ in the frequency range $1 \mathrm{~Hz}-1 \mathrm{MHz}$ using two different electrode types: (1) screen-printed electrode on an insulator substrate (arrowhead, AH); (2) two stainless steel needles, $1.5 \mathrm{~cm}$ long, featuring a $1 \mathrm{~mm}$ diameter and placed $1 \mathrm{~cm}$ apart (double 


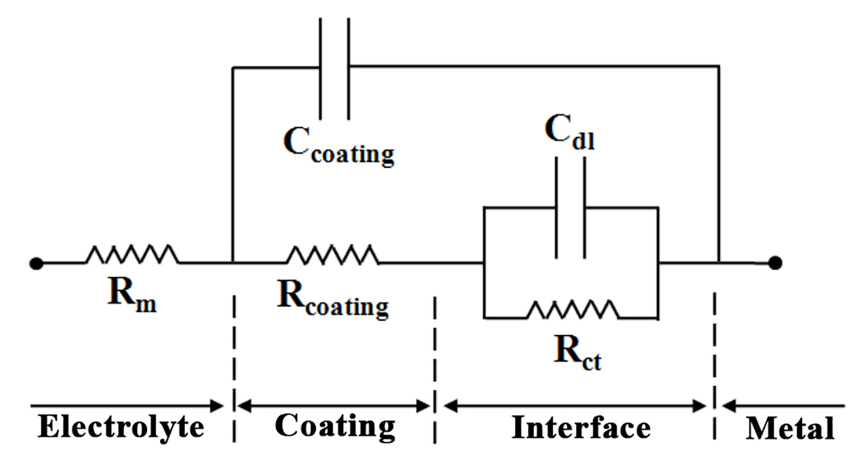

Figure 9. Equivalent circuit of a metal coated with an organic polymer in contact with an electrolyte.

electrode, DE). The AH electrode failed in the discrimination of fresh and frozen-thawed samples, while the DE electrode measurements with PCA and discriminant analysis (DA) were able to reliably discriminate between the two products, since frozen-thawed samples featured lower values of impedance modulus.

\section{Other EIS applications}

In the field of non-biological measurements, one of the most important EIS applications is corrosion monitoring of metal surfaces. To prevent corrosion in hostile environment (in particular acid electrolytes), metallic surfaces are often coated with organic polymers acting as protection barriers. With continued exposure, however, the acid electrolyte begins to penetrate, producing metal corrosion, loss of coating adhesion and coating delamination. In this context, EIS can be used to assess such a degradation as well as to estimate the quality of coating even before corrosion begins. For this purpose, a wide frequency range (from $\mathrm{mHz}$ to $\mathrm{MHz}$ ) is used with a three-electrode system where the WE is the coated metal, while the supporting electrolyte is the corroding liquid in contact with the coating. The AC stimulus is often superimposed on a DC voltage corresponding to the open circuit potential. The electrical circuit most frequently used to model such a system is shown in Fig. 9 (Loveday et al., 2004), where the electrolyte resistance $R_{\mathrm{m}}$ is usually very low (1-50 $\Omega$ ); the coating capacitance $C_{\text {coating }}$ tends to be rather low (in the $\mathrm{nF}$ range), since coating is usually thick in order to provide better protection; and the coating resistance $R_{\text {coating }}$ is very high when the coating is new (in the $\mathrm{G} \Omega$ range). Finally, the parallel of charge transfer resistance $\left(R_{\mathrm{ct}}\right)$ and double-layer capacitance $\left(C_{\mathrm{dl}}\right)$ describes the electrochemical process (corrosion) at the metal-coating interface.

The coating degradation process can be divided into three different phases. In phase I, the coating is new and no corrosion is present at the metal-coating interface. Under these conditions, the system can be modeled as the series of $R_{\mathrm{m}}$ and the parallel of $R_{\text {coating }}$ and $C_{\text {coating. The contact with }}$ the coating surface allows the electrolyte to slowly penetrate; thus, $C_{\text {coating }}$ increases (due to absorbed water) while $R_{\text {coating }}$ decreases (due to the formation of conductive paths in the coating structure). When the electrolyte has deeply penetrated the coating and a portion of the metal substrate is contacted, corrosion reaction starts and phase II begins, with decreasing $R_{\text {ct }}$ (because of increased reaction rate at the metal interface) and increasing $C_{\mathrm{dl}}$. As the corrosion process continues, the system enters phase III where an ever-increasing portion of the metal surface is corroded and loss of coating adhesion as well as delamination take place. During phase III, the electrical parameter variation is highly dependent on type of coating, metal and electrolyte involved in the process.

In literature, many papers are available about the use of EIS to investigate underpaint corrosion (Sekine, 1997; Bonora et al., 1995) and to detect the degree of coating delamination (McIntyre and Pham, 1996).

To monitor underpaint corrosion, all the parameters of the electrical model must be taken into account. Thus, they must be extracted by means of non-linear iterative least squares algorithms used to fit the measured data with the equivalent circuit model. This process, however, is time consuming and needs dedicated software packages; hence, it not suitable to be implemented in portable devices for in situ corrosion monitoring. For this reason, many authors have investigated the possibility to use only raw impedance data. Mahdavian and Attar (2006) found that the phase angle at $10 \mathrm{kHz}$ can be used to estimate coating resistance and capacitance; Zuo et al. (2008) extended the investigations of Mahadavian and Attar and discussed how the phase angle measured at $10 \mathrm{~Hz}$ is correlated with the coating resistance, while the value measured at $15 \mathrm{kHz}$ can be used to detect the loss of coating protection; Akbarinezhad et al. (2009) suggested that the area under the Bode plot for $|Z|$ and $\operatorname{Arg}(Z)$ provides a parameter for ranking the performance of organic coating; Zhang et al. (2005) discussed how the breakpoint frequency (i.e., that at which the phase angle equals $45^{\circ}$ ) is proportional to the delaminated area and inversely proportional to coating resistivity and permittivity; Zhao et al. (2007) used the changing rate of impedance in conjunction with the self-organizing feature map network for the analysis of the coating deterioration process. An handheld system for in situ corrosion monitoring, based on the microcontroller MSP430F149 and capable of measuring impedances in the range $1 \mathrm{k} \Omega-10 \mathrm{G} \Omega$ was built by Angelini et al. (2006).

A different, but related, EIS application is the investigation of corrosion inhibition efficiency by different compounds. In this case, the metal surface is exposed to the electrolyte without any coating and different concentrations of the investigated compound are added. The system can be modeled with the electrical circuit of Fig. $3 \mathrm{~b}$ and the most useful parameter is $R_{\mathrm{ct}}$ (increasing with corrosion inhibition). The compound 


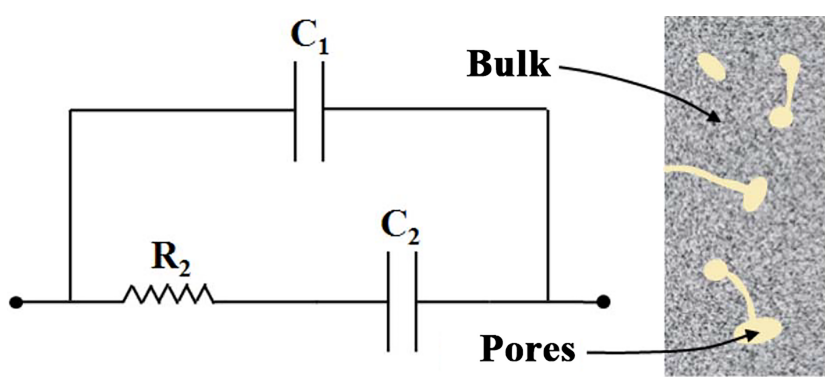

Figure 10. Equivalent circuit used to investigate the hardening process of cement paste.

inhibition efficiency can be defined as

$\eta=\frac{R_{\mathrm{ct}}^{*}-R_{\mathrm{ct}}}{R_{\mathrm{ct}}^{*}} \times 100$

where $R_{\mathrm{ct}}^{*}$ and $R_{\mathrm{ct}}$ are the charge transfer resistance in the presence and in the absence of the inhibition compound, respectively.

In particular, this technique has been used in the case of mild steel in contact with acid electrolyte (such as $\mathrm{HCl}$ and $\mathrm{H}_{2} \mathrm{SO}_{4}$ ) to test inhibition efficiency for different compounds: caffeic acid (de Souza and Spinelli, 2009); plant leaf extract, such as henna (Lawsonia inermis) (Ostovari et al., 2009), Justicia gendarussa (Satapathy et al., 2009) and Aquilaria crassna (Helen et al., 2014); ultrafiltrated oil palm frond lignins (Hussin et al., 2016); pyridine (Ansari et al., 2015) and pyrazine (Bouklah et al., 2005) derivatives as well as different synthesized Schiff bases (Dasami et al., 2015; Singh and Quraishi, 2016).

Another EIS application is characterization of the hardening process of cement paste (Andrade et al., 1999). This investigation is usually carried out by means of a twoelectrode configuration with a cylinder of cement paste between two graphite electrodes: between the cement paste and the electrodes a narrow separation exists (air gap or insulating polyester sheets) to eliminate any contribution of the cement-electrode interface. Under these conditions, the electrical model for the system is shown in Fig. 10 , where $C_{1}$ accounts for the dielectric capacitance associated with the solid phase, while $R_{2}$ and $C_{2}$ are the resistive and capacitive components of the electrolyte filling cement pores. This electrical model is valid at frequencies lower than $15 \mathrm{MHz}$, since for higher frequencies the system response features multiple time constants (Keddam et al., 1999). According to Cabeza et al. (2002, 2006), during the cement drying process, the capacitance $C_{1}$ (depending on sample thickness and porosity) presents no significant variation, while $C_{2}$ features an irregular and noisy behavior and $R_{2}$ increases with hardening. Zhang et al. (2015) showed how EIS can be used to detect cracks in concrete structures.

EIS is also widely used in battery management systems, where the state of charge (SOC) and state of health (SOH)

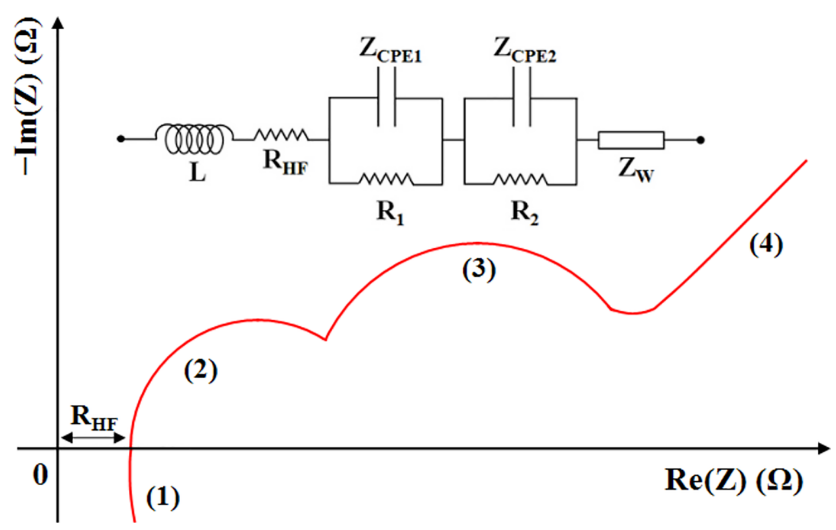

Figure 11. Equivalent circuit and Nyquist plot of a lithium-ion battery cell.

can be estimated by looking at the cell electrical parameters (Huet, 1998; Rodrigues et al., 2000). In the literature, no single established electrical circuit is present to model the investigated cell, since different battery technologies (i.e., leadacid, nickel-cadmium, lithium-ion) are based on different chemical reactions. However, the electrical model of Fig. 11 can be used for lithium-ion cells (Andre et al., 2011).

EIS investigations on batteries are usually carried out in the frequency range from a few $\mathrm{mHz}$ (or even tens of $\mu \mathrm{Hz}$ ) to several tens of $\mathrm{kHz}$. In the high-frequency range, the response is dominated by the cell inductance $L$ (phase $\mathrm{I}$ in Fig. 11), while at low frequency the ion diffusion inside the battery is the main process, to be modeled by the Warburg impedance $Z_{\mathrm{W}}$ (phase IV). At middle frequencies, the Nyquist plot is described by two semicircles (each modeled by the parallel of a charge transfer resistance and a CPE) representing the reactions at the two electrodes.

The high-frequency resistance $R_{\mathrm{HF}}$, modeling the ohmic resistance of the electrolyte, has been widely used to estimate the SOC of different batteries such as lead-acid (Barton and Mitchell, 1989) and nickel-cadmium (Diard et al., 1998) since such a parameter can be measured at relatively high frequency (about $1 \mathrm{kHz}$ ) in a short time; in both cases, however, the $R_{\mathrm{HF}}$ versus SOC curve is strongly non-linear and the $R_{\mathrm{HF}}$ sensitivity to SOC is non-negligible only for low values of SOC.

Better results have been obtained by Ran et al. (2010), where SOC of lithium-ion cells has been estimated using different parameters, such as the frequency of maximum of the Nyquist plot semicircle, the phase angle and the equivalent series capacitance.

Cuadras et al. proposed a technique, based on the phase variation of the measured impedance, to estimate SOC (Cuadras and Kanoun, 2009) and SOH (Cuadras et al., 2008) in lithium-ion cells.

Furthermore, studies have also been done for the characterization and diagnosis of proton exchange membrane fuel cells (Yuan et al., 2007), solid oxide fuel cells (Huang et 
al., 2007), biofuel cells (Kashyap et al., 2014), solar cells (Fabregat-Santiago et al., 2005; Glatthaar et al., 2005; Rock et al., 2014) and microbial fuel cells (He and Mansfeld, 2009).

Finally, EIS is also used to characterize different electronic devices such as organic semiconductors (Chandra et al., 2007; Garcia-Belmonte et al., 2008) and supercapacitors (Barsali et al., 2010) to assess the stability of emulsions (Roldan-Cruz et al., 2016) and to estimate the oil concentration in metalworking fluids (Grossi and Riccò, 2017).

\section{Conclusions}

A review of EIS particularly focused on its many applications in both biologic and non-biologic fields has been presented. The response to an electrical stimulus applied to the sample under test in a wide range of frequencies provides an electrical fingerprint of the investigated material and can be used to estimate useful parameters.

A number of applications has been reviewed. In the field of bacterial contamination analysis, the microbial concentration is estimated either by the changes in the medium electrical parameters due to bacterial metabolism (impedance mi- crobiology) or by measuring the charge transfer resistance of an electrode with an immobilized bioreceptor (impedance biosensor): while the first case is suitable for easy implementation in the form of an embedded electronic system, the second is more complex but results in shorter time response and improved selectivity towards specific bacterial strains. The application of EIS to the analysis of human body composition provides quick, non-invasive tools for health monitoring and early detection of potential pathologies. In the field of food screening for quality assessment, EIS offers an alternative to laboratory analysis for a wide range of products, avoiding sample shipments with significant advantages in terms of shorter time response and cost savings. Finally, in the case of corrosion analysis and battery management, EIS offers the possibility of low-cost portable electronic system for online monitoring.

While the presented applications are those most discussed in literature, a large number of others also exist, making EIS a very useful and versatile tool for material investigation.

Data availability. No data sets were used in this article. 
Appendix A: Abbreviations

$\begin{array}{ll}\text { ADC } & \text { Analog-to-digital converter } \\ \text { BIA } & \text { Bioelectrical impedance analysis } \\ \text { BIS } & \text { Bioelectrical impedance spectroscopy } \\ \text { CE } & \text { Counter electrode } \\ \text { CPE } & \text { Constant phase element } \\ \text { DA } & \text { Discriminant analysis } \\ \text { DAC } & \text { Digital-to-analog converter } \\ \text { DEP } & \text { Dielectrophoresys } \\ \text { DT } & \text { Detect time } \\ \text { ECW } & \text { Extracellular water } \\ \text { EIS } & \text { Electrical impedance spectroscopy } \\ \text { FEF } & \text { Fringing electric field } \\ \text { FFM } & \text { Fat-free mass } \\ \text { FM } & \text { Fat mass } \\ \text { ICW } & \text { Intracellular water } \\ \text { IDA } & \text { Interdigitated array } \\ \text { IM } & \text { Impedance microbiology } \\ \text { KK } & \text { Kramers-Kronig relation } \\ \text { LTI } & \text { Linear time invariant } \\ \text { MF-BIA } & \text { Multi-frequency BIA } \\ \text { PBS } & \text { Phosphate-buffered saline } \\ \text { PCA } & \text { Principal component analysis } \\ \text { PCT } & \text { Plate count technique } \\ \text { PLS } & \text { Partial least squares } \\ \text { RE } & \text { Reference electrode } \\ \text { SAM } & \text { Self-assembled monolayer } \\ \text { SEG-BIA } & \text { Segmental BIA } \\ \text { SF-BIA } & \text { Single-frequency BIA } \\ \text { SOC } & \text { State of charge } \\ \text { SOH } & \text { State of health } \\ \text { SUT } & \text { Sample under test } \\ \text { TBW } & \text { Total body water } \\ \text { WE } & \text { Working electrode } \\ \text { WSE } & \text { Working sensing electrode } \\ & \end{array}$


Competing interests. The authors declare that they have no conflict of interest.

Edited by: Marco Jose da Silva

Reviewed by: three anonymous referees

\section{References}

Akbarinezhad, E., Bahremandi, M., Faridi, H. R., and Rezaei, F.: Another approach for ranking and evaluating organic paint coatings via electrochemical impedance spectroscopy, Corros. Sci., 51, 356-363, 2009.

Alocilja, E. C. and Radke, S. M.: Market analysis of biosensors for food safety, Biosens. Bioelectron., 18, 841-846, 2003.

Alonso-Arce, M., Legarda, J., Sedano, B., and Bustamante, P.: Ultra Low-Power Smart Medical Sensor Node for In-Body Biomonitoring, IEEE 15th International Conference on e-Health Networking, Applications and Services (Healthcom), 491-496, 2013.

Amirudin, A. and Thieny, D.: Application of electrochemical impedance spectroscopy to study the degradation of polymercoated metals, Prog. Org. Coat., 26, 1-28, 1995.

Andrade, C., Blanco, V. M., Collazo, A., Keddam, M., Novoa, X. R., and Takenouti, H.: Cement paste hardening process studied by impedance spectroscopy, Electrochim. Acta, 44, 4313-4318, 1999.

Andre, D., Meiler, M., Steiner, K., Walz, H., Soczka-Guth, T., and Sauer, D. U.: Characterization of high-power lithium-ion batteries by electrochemical impedance spectroscopy, II: Modelling, J. Power Sources, 196, 5349-5356, 2011.

Angelini, E., Carullo, A., Corbellini, S., Ferraris, F., Gallone, V., Grassini, S., Parvis, M., and Vallan, A.: Handheld-impedancemeasurement system with seven-decade capability and potentiostatic function, IEEE T. Instrum. Meas., 55, 436-441, 2006.

Ansari, K. R., Quraishi, M. A., and Singh, A.: Pyridine derivatives as corrosion inhibitors for $\mathrm{N} 80$ steel in $15 \% \mathrm{HCl}$ : Electrochemical, surface and quantum chemical studies, Measurement, 76, 136-147, 2015.

Atmanand, M. A. and Jagadeesh Kumar, V.: Microcontroller based LCR meter, Microprocessors and Microsystems, 20, 297-301, 1996.

Atmanand, M. A., Jagadeesh Kumar, V., and Murti, V. G. K.: A microcontroller-based scheme for measurement of $\mathrm{L}$ and $\mathrm{C}$, Meas. Sci. Technol., 6, 576-581, 1995.

Barreiros dos Santos, M., Sporer, C., Sanvicens, N., Pascual, N., Errachild, A., Martinez, E., Marco, M. P., Teixeira, V., and Samiter, J.: Detection of pathogenic Bacteria by Electrochemical Impedance Spectroscopy: Influence of the immobilization strategies on the sensor performance, Procedia Chemistry - Proceedings of the Eurosensors XXIII conference, 1, 1291-1294, 2009.

Barsali, S., Ceraolo, M., Marracci, M., and Tellini, B.: Frequency dependent parameter model of supercapacitor, Measurement, 43, 1683-1689, 2010.

Barsoukov, E. and Macdonald, J. R.: Impedance Spectroscopy: Theory, Experiment, and Applications, 2nd Edn., John Wiley \& Sons, 2005.

Barton, R. and Mitchell, P.: Estimation of the residual capacity of maintenance-free lead acid batteries, Part 1: Identification of a parameter for the prediction of state-of-charge, J. Power Sources, 27, 287-295, 1989.

Bauchot, A. D., Harker, F. R., and Arnold, W. M.: The use of electrical impedance spectroscopy to assess the physiological condition of kiwifruit, Postharvest Biol. Tec., 18, 9-18, 2000.

Bhatt, C. M. and Nagaraju, J.: Instrumentation to estimate the moisture content in bread using electrical impedance spectroscopy, Sensors Transd. J., 97, 45-54, 2008.

Bhatt, C. M. and Nagaraju, J.: Non-destructive method to estimate the moisture content in bread using multi-channel electrical impedance spectroscopy, IEEE Sensors Applications Symposium (SAS), New Orleans, LA, USA, 17-19 February, 2009.

Bogonez, P. and Riu, P. J.: Implantable bioimpedance system for measuring impedance of kidney, Proceedings of the 13th International Conference on Electrical Bioimpedance and the 8th Conference on Electrical Impedance Tomography, Springer Berlin Heidelberg, 256-259, 2007.

Bonora, P. L., Deflorian, F., and Fedrizzi, L.: Electrochemical impedance spectroscopy as a tool for investigating underpaint corrosion, Electrochim. Acta, 41, 1073-1082, 1995.

Boukamp, B. A.: A linear Kronig-Kramers transform test for immittance data validation, J. Electrochem. Soc., 142, 1885-1894, 1995.

Bouklah, M., Attayibat, A., Kertit, S., Ramdani, A., and Hammouti, B.: A pyrazine derivative as corrosion inhibitor for steel in sulphuric acid solution, Appl. Surf. Sci., 242, 399-406, 2005.

Breniuc, L., David, V., and Haba, C.-G.: Wearable Impedance Analyzer Based on AD5933, International Conference and Exposition on Electrical and Power Engineering (EPE), Iasi, Romania, 16-18 October 2014, 585-590, 2014.

Breugelmans, T., Tourwé, E., Van Ingelgem, Y., Wielant, J., Hauffman, T., Haubrand, R., Pintelon, R., and Hubin, A.: Odd random phase multisine EIS as a detection method for the onset of corrosion of coated steel, Electrochem. Comm., 12, 2-5, 2010.

Cabeza, M., Merino, P., Miranda, A., Novoa, X. R., and Sanchez, I.: Impedance spectroscopy study of hardened Portland cement paste, Cement Concrete Res., 32, 881-891, 2002.

Cabeza, M., Keddam, M., Novoa, X. R., Sanchez, I., and Takenouti, H.: Impedance spectroscopy to characterize the pore structure during the hardening process of Portland cement paste, Electrochim. Acta, 51, 1831-1841, 2006.

Cady, P.: Progress in impedance measurements in microbiology, in: Mechanizing microbiology, Chapter 14, edited by: Sharpe, A. N. and Clark, D. S., Charles C. Thomas Publisher, 199-239, 1978.

Chandra, K. P., Prasad, K., and Gupta, R. N.: Impedance spectroscopy study of an organic semiconductor: Alizarin, Physica B, 388, 118-123, 2007.

Chanet, M., Riviere, C., and Eynard, P.: Electric impedance spectrometry for the control of manufacturing process of comminuted meat products, J. Food Eng., 42, 153-159, 1999.

Chang, B. Y. and Park, S. M.: Electrochemical Impedance Spectroscopy, Ann. Rev. Anal. Chem., 3, 207-229, 2010.

Chinen, K., Kinjo, I., Zamami, A., Irei, K., and Nagayama, K.: New equivalent-electrical circuit model and a practical measurement method for human body impedance, Biomed. Mat. Eng., 26, 779-786, 2015.

Choi, A., Park, J. S., and Jung, H. I.: Solid-medium-integrated impedimetric biosensor for real-time monitoring of microorganisms, Sensor. Actuat. B-Chem., 137, 357-362, 2009. 
Chowdhury, A., Kanti Bera, T., Ghoshal, D., and Chakraborty, B.: Electrical impedance variations in banana ripening: an analytical study with electrical impedance spectroscopy, J. Food Process. Eng., 40, e12387, https://doi.org/10.1111/jfpe.12387, 2017a.

Chowdhury, A., Singh, P., Kanti Bera, T., Ghoshal, D., and Chakraborty, B.: Electrical impedance spectroscopy study of mandarin orange during ripening, J. Food Meas. Charact., 1-11, https://doi.org/10.1007/s11694-017-9545-y, 2017b.

Christensen, B. J., Coverdale, T., Olson, R. A., Ford, S. J., Garboczi, E. J., Jennings, H. M., and Mason, T. O.: Impedance Spectroscopy of Hydrating Cement-Based Materials: Measurement, Interpretation, and Application, J. Am. Ceram. Soc., 77, 27892804, 1994.

Chuang, C.-H., Du, Y.-C., Wu, T.-F., Chen, C.-H., Lee, D.-H., Chen, S.-M., Huang, T.-C., Wu, H.-P., and Shaikh, M. O.: Immunosensor for the ultrasensitive and quantitative detection of bladder cancer in point of care testing, Biosens. Bioelectron., 84, 126132, 2016.

Clemente, F., Arpaia, P., and Manna, C.: Characterization of human skin impedance after electrical treatment for transdermal drug delivery, Measurement, 46, 3494-3501, 2013.

Clemente, F., Romano, M., Bifulco, P., and Cesarelli, M.: EIS measurements for characterization of muscular tissue by means of equivalent electrical parameters, Measurement, 58, 476-482, 2014.

Cuadras, A. and Kanoun, O.: SoC Li-ion battery monitoring with impedance spectroscopy, Proceedings of the 6th International Multi-Conference on Systems, Signals and Devices, 1-5, 2009.

Cuadras, A., Troltzsch, U., and Kanoun, O.: Low energy budget battery monitoring, Proceedings of the XXII Eurosensors, 14901493, 2008.

Dasami, P. M., Parameswari, K., and Chitra, S.: Corrosion inhibition of mild steel in ${ }_{1} \mathrm{MH}_{2} \mathrm{SO}_{4}$ by thiadiazole Schiff bases, Measurement, 69, 195-201, 2015.

Dastider, S. G., Barizuddin, S., Yuksek, N. S., Dweik, M., and Almasri, M. F.: Efficient and Rapid Detection of Salmonella Using Microfluidic Impedance Based Sensing, J. Sensor., 2015, 293461, https://doi.org/10.1155/2015/293461, 2015.

de Souza, F. S. and Spinelli, A.: Caffeic acid as a green corrosion inhibitor for mild steel, Corros. Sci., 51, 642-649, 2009.

Deurenberg, P. and Deurenberg-Yap, M.: Validation of skinfold thickness and hand-held impedance measurements for estimation of body fat percentage among Singaporean, Chinese, malay and Indian subjects, Asia Pac. J. Clin. Nutr., 11, 1-7, 2002.

Diard, J.-P., Le Gorrec, B., and Montella, C.: EIS study of electrochemical battery discharge on constant load, J. Power Sources, 70, 78-84, 1998.

Dong, J., Zhao, H., Xu, M., Ma, Q., and Ai, S.: A label-free electrochemical impedance immunosensor based on AuNPs/PAMAMMWCNT-Chi nano composite modified glassy carbon electrode for detection of Salmonella typhimurium in milk, Food Chem., 141, 1980-1986, 2013.

Durante, G., Becari, W., Lima, F. A. S., and Peres, H. E. M.: Electrical Impedance Sensor for Real-Time Detection of Bovine Milk Adulteration, IEEE Sensors J., 16, 861-865, 2016.

Dzwonczyk, R., Hartzler, A. W., and Liu, A. Y.: A new apparatus and method for measuring the myocardial electrical impedance spectrum, Proceedings of Computers in Cardiology, Durham, NC, USA, USA, 11-14 October, 1992.
Fabregat-Santiago, F., Bisquert, J., Garcia-Belmonte, G., Boschloo, G., and Hagfeldt, A.: Influence of electrolyte in tran sport and recombination in dye.sensitized solar cells studied by impedance spectroscopy, Sol. Energ. Mat. Sol. C., 87, 117-131, 2005.

Fasmin, F. and Srinivasan, R.: Review - Nonlinear Electrochemical Impedance Spectroscopy, J. Electrochem. Soc., 164, 443-455, 2017.

Ferreira, J., Seoane, F., Ansede, A., and Bragos, R.: AD5933based Spectrometer for Electrical Bioimpedance Applications, International Conference on Electrical Bioimpedance, J. Phys. Conf. Ser., 224, 012011, https://doi.org/10.1088/17426596/224/1/012011, 2010.

Ferreira, J., Seoane, F., and Lindecrantz, K.: AD5933-Based Electrical Bioimpedance Spectrometer Towards Texttile-Enabled Applications, Proceedings of the 33rd Annual International Conference of the IEEE EMBS, Boston, Massachusetts, USA 30 August-3 September 2011, 3282-3285, 2011.

Ferrero, F. J., Valledor, M., and Campo, J. C.: Screening method for early detection of mastitis in cows, Measurement, 47, 855-860, 2014.

Fistenberg-Eden, R.: Rapid estimation of the number of microorganisms in raw meat by impedance measurement, Food Technol., 37, 64-70, 1983.

Fistenberg-Eden, R. and Eden, G.: Impedance Microbiology, John Wiley, New York, 1984.

Fuentes, A., Masot, R., Fernandez-Segovia, I., Ruiz-Rico, M., Alcaniz, M., and Barat, J. M.: Differentiation between fresh and frozen-thawed sea bream (Sparus aurata) using impedance spectroscopy techniques, Innov. Food Sci. Emerg. Technol., 19, 210217, 2013.

Garcia-Belmonte, G., Munar, A., Barea, E. M., Bisquert, J., Ugarte, I., and Pacios, R.: Charge carrier mobility and lifetime of organic bulk heterojunctions analyzed by impedance spectroscopy, Org. Electron., 9, 847-851, 2008.

Gervais, L., Gel, M., Allain, B., Tolba, M., Brovko, L., Zourob, M., Mandeville, R., Griffiths, M., and Evoy, S.: Immobilization of biotinylated bacteriophages on biosensor surfaces, Sensor. Actuat. B-Chem., 125, 615-621, 2007.

Ghosh, S., Meister, D., Cowen, S., Hannan, J. W., and Ferguson, A.: Body composition at the bedside, Eur. J. Gastroenterol. Hepatol., 9, 783-788, 1997.

Glatthaar, M., Mingirulli, N., Zimmermann, B., Ziegler, T., Kern, R., Niggemann, M., Hinsch, A., and Gombert, A.: Impedance spectroscopy on organic bulk-heterojunction solar cells, Phys. Status Solidi A, 202, 125-127, 2005.

Gomez-Sjoberg, R., Morisette, D. T., and Bashir, R.: Impedance Microbiology-on-a-Chip: Microfluidic Bioprocessor for Rapid Detection of Bacterial Metabolism, J. Microelectromech. S., 14, 829-838, 2005.

Grossi, M. and Riccò, B.: An automatic titration system for oil concentration measurement in metalworking fluids, Measurement, 97, 8-14, 2017.

Grossi, M., Lanzoni, M., Pompei, A., Lazzarini, R., Matteuzzi, D., and Riccò, B.: Detection of microbial concentration in ice-cream using the impedance technique, Biosens. Bioelectron., 23, 16161623, 2008.

Grossi, M., Pompei, A., Lanzoni, M., Lazzarini, R., Matteuzzi, D., and Riccò, B.: Total bacterial count in soft-frozen dairy products 
by impedance biosensor system, IEEE Sensors J., 9, 1270-1276, 2009.

Grossi, M., Lanzoni, M., Pompei, A., Lazzarini, R., Matteuzzi, D., and Riccò, B.: An embedded portable biosensor system for bacterial concentration detection, Biosens. Bioelectron., 26, 983-990, 2010.

Grossi, M., Lazzarini, R., Lanzoni, M., and Riccò, B.: A novel technique to control ice-cream freezing by electrical characteristics analysis, J. Food Eng., 106, 347-354, 2011a.

Grossi, M., Lanzoni, M., Pompei, A., Lazzarini, R., Matteuzzi, D., and Riccò, B.: A portable biosensor system for bacterial concentration measurements in cow's raw milk, Proceedings of the 4th IEEE International Workshop on Advances in Sensors and Interfaces, 132-136, 2011b.

Grossi, M., Lanzoni, M., Lazzarini, R., and Riccò, B.: Linear non iterative sinusoidal fitting algorithm for microbial impedance biosensor, Sens. Transducers J., 137, 235-244, 2012a.

Grossi, M., Lanzoni, M., Lazzarini, R., and Riccò, B.: Automatic ice-cream characterization by impedance measurements for optimal machine setting, Measurement, 45, 1747-1754, 2012b.

Grossi, M., Lazzarini, R., Lanzoni, M., Pompei, A., Matteuzzi, D., and Riccò, B.: A portable sensor with disposable electrodes for water bacterial quality assessment, IEEE Sensors J., 13, 17751781, 2013a.

Grossi, M., Di Lecce, G., Gallina Toschi, T., and Riccò, B.: A novel electrochemical method for olive oil acidity determination, Proceedings of the IEEE International Workshop on Advances in Sensors and Interfaces (IWASI), Bari (BR), Italy, 13-14 June 2013, 162-167, 2013b.

Grossi, M., Di Lecce, G., Gallina Toschi, T., and Riccò, B.: Fast and Accurate Determination of Olive Oil Acidity by Electrochemical Impedance Spectroscopy, IEEE Sensors J., 14, 2947-2954, 2014a.

Grossi, M., Di Lecce, G., Gallina Toschi, T., and Riccò, B.: A novel electrochemical method for olive oil acidity determination, Microelectr. J., 45, 1701-1707, 2014b.

Grossi, M., Parolin, C., Vitali, B., and Riccò, B.: Bacterial concentration detection using a portable embedded sensor system for environmental monitoring, Proceedings of the 7th IEEE International Workshop on Advances in Sensors and Interfaces (IWASI), Vieste (FG), Italy, 15-16 June 2017, 246-251, 2017.

Gudivaka, R., Schoeller, D. A., Kushner, R. F., and Bolt, M. J. G.: Single and multifrequency models for bioelectrical impedance analysis of body water compartments, J. Appl. Physiol., 87, 1087-1096, 1999.

Guyader, A., Huet, F., and Nogueira, R. P.: Polarization resistance measurements: Potentiostatically or galvanostatically?, Corrosion, 65, 136-144, 2009.

Hall, J. L., Flowers, T. J., and Robert, R. M.: Plant cell structure and metabolism, 1st Edn., Longman Group Limited, London, 1974.

Hanai, T.: Electrical properties of emulsions, mulsion science, edited by: Sherman, P. H., Academic, UK, 354-477, 1968.

Hannan, W. J., Cowen, S. J., Fearson, K. C. H., Plester, C. E., Falconer, J. S., and Richardson, R. A.: Evaluation of multifrequency bioimpedance analysis for the assessment of extracellular and total body water in surgical patients, Clin. Sci., 86, 479485, 1994.

Hardy, D., Kraeger, S. J., Dufour, S. W., and Cady, P.: Rapid Detection of Microbial Contamination in Frozen Vegetables by Au- tomated Impedance Measurements, Appl. Environ. Microb., 34, 14-17, 1977.

Harker, F. R. and Forbes, S. K.: Ripening and development of chilling injury in persimmon fruit: an electrical impedance study, New Zeal. J. Crop Hort., 25, 149-157, 1997.

Harker, F. R. and Maindonald, J. H.: Ripening of nectarine fruit, Plant Physiol., 106, 165-171, 1994.

Haußmann, P. and Melbert, J.: Optimized mixed-domain signal synthesis for broadband impedance spectroscopy measurements on lithium ion cells for automotive applications, J. Sens. Sens. Syst., 6, 65-76, 2017.

Haverkort, E. B., Reijven, P. L. M., Binnekade, J. M., de van der Schueren, M. A. E., Earthman, C. P., Gouma, D. J., and de Haan, R. J.: Bioelectrical impedance analysis to estimate body composition in surgical and oncological patients: a systematic review, Eur. J. Clin. Nutr., 69, 3-13, 2015.

Hayden, R. I., Moyse, C. A., Calder, F. W., Crawford, D. P., and Fensom, D. S.: Electrical studies on potato and alfalfa tissue, J. Exp. Bot., 20, 177-200, 1969.

He, Z. and Mansfeld, F.: Exploring the use of electrochemical impedance spectroscopy (EIS) in microbial fuel cell studies, Energy Environ. Sci., 2, 215-219, 2009.

Helen, L. Y. S., Rahim, A. A., Saad, B., Saleh, M. I., and Bothi Raja, P.: Aquilaria Crassna leaves extracts - a green corrosion inhibitor for mild steel in $1 \mathrm{M} \mathrm{HCl}$ medium, Int. J. Electrochem. Sci., 9, 830-846, 2014.

Hoffer, E. C., Meador, C. K., and Simpson, D. C.: Correlation of whole-body impedance with total body water volume, J. Appl. Physiol., 27, 531-534, 1969.

Hoja, J. and Lentka, G.: Portable Analyzer for Impedance Spectroscopy, Proceedings of the XIX IMEKO World Congress Fundamental and Applied Metrology, Lisbon, Portugal, 6-11 September 2009, 497-502, 2009.

Howie, M. B., Dzwonczyk, R., and McSweeney, T. D.: An evaluation of a new two-electrode myocardial electrical impedance monitor for detecting myocardial ischemia, Anesth. Analg., 92, 12-18, 2001.

Huang, Q.-A., Hui, R., Wang, B., and Zhang, J.: A review of AC impedance modeling and validation in SOFC diagnosis, Electrochem. Acta, 52, 8144-8164, 2007.

Huet, F.: A review of impedance measurements for determination of the state-of-charge or state-of-health of secondary batteries, J. Power Sources, 70, 59-69, 1998.

Hussin, M. H., Rahim, A. A., Nasir, M., Ibrahim, M., and Brosse, N.: The capability of ultrafiltrated alkaline and organosolv oil palm (Elais guineensis) fronds lignin as green corrosion inhibitor for mild steel in $0.5 \mathrm{M} \mathrm{HCl}$ solution, Measurement, 78, 90-103, 2016.

Ibrahim, F., Nasir Taib, M., Bakar Wan Abas, W. A., Guan, C. C., and Sulaiman, S.: A Novel Approach to Classify Risk in Dengue Hemorrhagic Fever (DHF) Using Bioelectrical Impedance Analysis (BIA), IEEE T. Instrum. Meas., 54, 237-244, 2005.

Jackson, P. J. and Harker, F. R.: Apple bruise detection by electrical impedance measurement, HortScience, 35, 104-107, 2000.

Jaffrin, M. Y. and Morel, H.: Body fluid volumes measurements by impedance: A review of bioimpedance spectroscopy (BIS) and bioimpedance analysis (BIA) methods, Med. Eng. Phys., 30, 1257-1269, 2008. 
Juansah, J., Budiastra, I. W., Dahlan, K., and Seminar, K. B.: Electrical behavior of garut citrus fruit during ripening changes in resistance and capacitance models of internal fruits, Int. J. Eng. Tech., 12, 1-8, 2012.

Kagawa, M., Wishart, C., and Hills, A. P.: Influence of Posture and Frequency Modes in Total Body Water Estimation Using Bioelectrical Impedance Spectroscopy in Boys and Adult Males, Nutrients, 6, 1886-1898, 2014.

Kamat, D. K., Bagul, D., and Patil, P. M.: Blood Glucose Measurement Using Bioimpedance Technique, Adv. Electron., 2014, 1-5, 2014

Kanti Bera, T.: Bioelectrical Impedance Methods for Noninvasive Health Monitoring: A Review, J. Med. Eng., 2014, 381251, https://doi.org/10.1155/2014/381251, 2014.

Kashyap, D., Dwivedi, P. K., Pandey, J. K., Kim, Y. H., Kim, G. M., Sharma, A., and Goel, S.: Application of electrochemical impedance spectroscopy in bio-fuel cell characterization: a review, Int. J. Hydrogen Energ., 39, 20159-20170, 2014.

Kaspar, C. W. and Tartera, C.: Methods in Microbiology, edited by: Grigorova, R. and Norris, J. R., London, Academic press, 497$531,1990$.

Keddam, M., Takenouti, H., Novoa, X. R., Andrade, C., and Alonso, C.: Impedance measurements on cement paste, Cement Concrete Res., 27, 1191-1201, 1999.

Khalil, S. F., Mohktar, M. S., and Ibrahim, F.: The Theory and Fundamentals of Bioimpedance Analysis in Clinical Status Monitoring and Diagnosis of Diseases, Sensors, 14, 10895-10928, 2014.

Kitamura, Y., Toyoda, K., and Park, B.: Electrical impedance spectroscopy for yogurt processing, Food Sci. Technol. Res., 6, 310313,2000

Kyle, U. G., Bosaeus, I., De Lorenzo, A. D., Deurenberg, P., Elia, M., Gomez, J. M., Heitmann, B. L., Kent-Smith, L., Melchior, J. C., Pirlich, M., Scharfetter, H., Schols, A., and Pichard, C.: Bioelectrical impedance analysis - part 1: review of principles and methods, Clin. Nutr., 23, 1226-1243, 2004.

Kyle, U. G., Genton, L., Karsegard, L., Slosman, D. O., and Pichard, C.: Single prediction equation for bioelectrical impedance analysis in adults aged 20-94 years, Nutrition, 17, 248-253, 2011.

Johnson, N., Chang, Z., Bravo Almeida, C., Michel, M., Iversen, C., and Callanan, M.: Evaluation of indirect impedance for measuring microbial growth in complex food matrices, Food Microbiol., 42, 8-13, 2014.

Labavitch, J. M., Greve, L. C., and Mitcham, E.: Fruit bruising: It's more than skin deep, Perishables Handling Quarterly, 95, 7-9, 1998.

Land, R., Annus, P., and Min, M.: Time-frequency impedance spectroscopy: excitation considerations, Proceedings of the IMEKO TC4 International Symposium on Novelties in Electrical Measurements and Instrumentations, 2007.

Li, D., Feng, Y., Zhou, L., Ye, Z., Wang, J., Ying, Y., Ruan, C., Wang, R., and Li, Y.: Label-free capacitive immunosensor based on quartz crystal Au electrode for rapid and sensitive detection of Escherichia coli O157:H7, Anal. Chim. Acta, 687, 89-96, 2011.

Li, X., Zyuzin, A. S., and Mamishev, A. V.: Measuring moisture content in cookies using dielectric spectroscopy, Annual Report, Conference on Electrical Insulation and Dielectric Phenomena, Albuquerque, NM, USA, USA, 19-22 October 2003.
Li, X. B., Larson, S. D., Zyuzin, A. S., and Mamishev, A. V.: Design principles for multichannel fringing electric field sensors, IEEE Sensors J., 6, 434-440, 2006.

Lizhi, H., Toyoda, K., and Ihara, I.: Dielectric properties of edible oils and fatty acids as a function of frequency, temperature, moisture and composition, J. Food Eng., 88, 151-158, 2008.

Lizhi, H., Toyoda, K., and Ihara, I.: Discrimination of olive oil adulterated with vegetable oils using dielectric spectroscopy, J. Food Eng., 96, 167-171, 2010.

Lohmann, N., Weßkamp, P., Haußmann, P., Melbert, J., and Musch, T.: Electrochemical impedance spectroscopy for lithium-ion cells: test equipment and procedures for aging and fast characterization in time and frequency domain, J. Power Sources, 273, 613-623, 2015.

Loveday, D., Peterson, P., and Rodgers, B.: Evaluation of organic coatings with electrochemical impedance spectroscopy - part 2 : application of EIS to coatings, JCT CoatingsTech, 88-93, 2004.

Mabrook, M. F. and Petty, M. C.: Effect of composition on the electrical conductance of milk, J. Food Eng., 60, 321-325, 2003.

Mabrook, M. F., Darbyshire, A. M., and Petty, M. C.: Quality control of dairy products using single frequency admittance measurements, Meas. Sci. Technol., 17, 275-280, 2006.

Mahdavian, M. and Attar, M. M.: Another approach in analysis of paint coatings with EIS measurement: Phase angle at high frequencies, Corros. Sci., 48, 4152-4157, 2006.

Mancuso, M., Grossi, M., Rappazzo, A. C., Zaccone, R., Caruso, G., Riccò, B., and Bergamasco, A.: Development of a sensor for the detection of Escherichia coli in brackish waters, J. Coastal Life Medicine, 4, 200-202, 2016.

Margo, C., Katrib, J., Nadi, M., and Rouane, A.: A four-electrode low frequency impedance spectroscopy measurement system using the AD5933 measurement chip, Physiol. Meas., 34, 391-405, 2013.

McIntyre, J. M. and Pham, H. Q.: Electrochemical impedance spectroscopy; a tool for organic coatings optimizations, Prog. Org. Coat., 27, 201-207, 1996.

Mead, P. S., Slutsker, L., Dietz, V., McCaig, L. F., Bresce, J. S., Shapiro, C., Griffin, P. M., and Tauxe, R. V.: Food-related illness and death in the United States, Centers for Disease Control and prevention, Atlanta, GA, 2000.

Mialich, M. S., Faccioli Sicchieri, J. M., and Alceu, A. J. J.: Analysis of Body Composition: A Critical Review of the Use of Bioelectrical Impedance Analysis, Int. J. Clin. Nutr., 2, 1-10, 2014.

Min, M., Parve, T., Ronk, A., Annus, P., and Paavle, T.: Synchronous sampling and demodulation in an instrument for multifrequency bioimpedance measurement, IEEE Trans. Inst. Meas., 56, 1365-1372, 2007.

Min, M., Pliquett, U., Nacke, T., Barthel, A., Annus, P., and Land, R.: Broadband excitation for short-time impedance spectroscopy, Physiol. Meas., 29, 185-192, 2008.

Mortari, A., Adami, A., and Lorenzelli, L.: An unconventional approach to impedance microbiology: Detection of culture media conductivity variations due to bacteriophage generated lyses of host bacteria, Biosens. Bioelectron., 67, 615-620, 2015.

Nernst, W.: Methode zur Bestimmung von Dielektrizitatskonstanten, Zeitschrijtfur Elektrochemie, 14, 622-663, 1894.

Niu, J. and Lee, J. Y.: A new approach for the determination of fish freshness by electrochemical impedance spectroscopy, J. Food Sci., 65, 780-785, 2000. 
Orazem, M. E. and Tribollet, B.: Electrochemical Impedance Spectroscopy, John Wiley and Sons, 2008.

Ostovari, A., Hoseinieh, S. M., Peikari, M., Shadizadeh, S. R., and Hashemi, S. J.: Corrosion inhibition of mild steel in $1 \mathrm{M} \mathrm{HCl}$ solution by henna extract: a comparative study of the inhibition by henna and its constituents (Lawsone, Gallic acid, $\alpha$-D-Glucose and Tannic acid), Corros. Sci., 51, 1935-1949, 2009.

Park, S., Yun, C.-B., and Inman, D. J.: A Self-contained Active Sensor System for Health Monitoring of Civil Infrastructures, IEEE Sensors (EXCO), Daegu, Korea, 22-25 October 2006, 798-802, 2006.

Piasecki, T., Chabowski, K., and Nitsch, K.: Design, calibration and tests of versatile low frequency impedance analyser based on ARM microcontroller, Measurement, 91, 155-161, 2016.

Pliquett, U., Gersing, E., and Pliquett, F.: Evaluation of timedomain based impedance measurements on biological tissue, Biomed. Tech. 45, 6-13, 2000.

Pompei, A., Grossi, M., Lanzoni, M., Perretti, G., Lazzarini, R., Riccò, B., and Matteuzzi, D.: Feasibility of lactobacilli concentration detection in beer by automated impedance technique, MBAA Technical Quarterly, 49, 11-18, 2012.

Prevc, T., Cigic, B., Vidrih, R., Poklar Ulrih, N., and Segatin, N.: Correlation of basic oil quality indices and electrical properties of model vegetable oil systems, J. Agr. Food Chem., 61, 1135511362, 2013.

Puttaswamy, S. and Sengupta, S.: Rapid detection of bacterial proliferation in food samples using microchannel impedance measurements at multiple frequencies, Sensors and Instrumentation for Food Quality, 4, 108-118, 2010.

Radke, S. M. and Alocilja, E. C.: Design and Fabrication of a Microimpedance Biosensor for Bacterial Detection, IEEE Sensors J., 4, 434-440, 2004.

Rafiuddin, M. Z. I.: Preparation, characterization, electrical conductivity and dielectric studies of $\mathrm{Na}_{2} \mathrm{SO}_{4}$ and $\mathrm{V}_{2} \mathrm{O}_{5}$ composite solid electrolytes, Measurement, 81, 102-112, 2016.

Ragni, L., Iaccheri, E., Cevoli, C., Berardinelli, A., Bendini, A., and Gallina Toschi, T.: A capacitive technique to assess water content in extra virgin olive oils, J. Food Eng., 116, 246-252, 2013.

Ramirez, N., Regueiro, A., Arias, O., and Contreras, R.: Electrochemical impedance spectroscopy: An effective tool for a fast microbiological diagnosis, Biotecnologia Aplicada, 26, 72-78, 2008.

Randviir, E. P. and Banks, C. E.: Electrochemical impedance spectroscopy: an overview of bioanalytical applications, Anal. Method., 5, 1098-1115, 2013.

Ran, L., Junfeng, W., Haiying, W., and Gechen, L.: Prediction of state of charge of lithium-ion rechargeable battery with electrochemical impedance spectroscopy theory, Proceedings of the 5th IEEE Conference on Industrial Electronics and Applications, 684-688, 2010.

Rehman, M., Abu Izneid, A. J. A., Abdullah, M. Z., and Arshad, M. R.: Assessment of quality of fruits using impedance spectroscopy, Int. J. Food Sci. Tech., 46, 1303-1309, 2011.

Rock, S. E., Shi, X., Garland, J. E., and Roy, D.: Experimental considerations for temperature controlled measurements of fast charge recombination times in dye sensitized solar cells using open circuit voltage decay and impedance spectroscopy, Measurement, 53, 71-82, 2014.
Rodrigues, S., Munichandraiah, N., and Shukla, A. K.: A review of state-of-charge indication of batteries by means of a.c. impedance measurements, J. Power Sources, 87, 12-20, 2000.

Roldan-Cruz, C., Vernon-Carter, E. J., and Alvarez-Ramirez, J.: Assessing the stability of Tween 80-based O/W emulsions with cyclic voltammetry and electrical impedance spectroscopy, Colloids Surf. A Physicochem. Eng. Asp., 511, 145-152, 2016.

Rush, E. C., Crowley, J., Freitas, I. F., and Luke, A.: Validity of Hand-to-Foot Measurement of Bioimpedance: Standing Compared with Lying Position, Obesity, 14, 252-257, 2006.

Satapathy, A. K., Gunasekaran, G., Sahoo, S. C., Amit, K., and Rodrigues, P. V.: Corrosion inhibition by Justicia gendarussa plant extract in hydrochloric acid solution, Corros. Sci., 51, 28482856, 2009.

Schönleber, M., Klotz, D., and Ivers-Tiffée, E.: A method for improving the robustness of linear Kramers-Kronig validity tests, Electrochim. Acta, 131, 20-27, 2014.

Sekine, I.: Recent evaluation of corrosion protective paint films by electrochemical methods, Prog. Org. Coat., 31, 73-80, 1997.

Settu, K., Chen, C. J., Liu, J. T., Chen, C. L., and Tsai, J. Z.: Impedimetric method for measuring ultra-low E. coli concentrations in human urine, Biosens. Bioelectron., 66, 244-250, 2015.

Shabani, A., Zourob, M., Allain, B., Marquette, C. A., Lawrence, M. F., and Mandeville, R.: Bacteriophage-Modified Microarrays for the Direct Impedimetric Detection of Bacteria, Anal. Chem., 80, 9475-9482, 2008.

Shafer, K. J., Siders, W. A., Johnson, L. K., and Lukaski, H. C.: Validity of segmental multiple-frequency bioelectrical impedance analysis to estimate body composition of adults across a range of body mass indexes, Nutrition, 25, 25-32, 2009.

Silley, P. and Forsythe, S.: Impedance Microbiology - a rapid change for microbiologists, J. Appl. Bacteriol., 80, 233-243, 1996.

Simic, M.: Realization of Complex Impedance Measurement System Based on the Integrated Circuit AD5933, 21st Telecommunications forum TELFOR, Belgrade, Serbia, 26-28 November 2013, 573-576, 2013.

Singh, P. and Quraishi, M. A.: Corrosion inhibition of mild steel using Novel Bis Schiff0s Bases as corrosion inhibitors: Electrochemical and Surface measurement, Measurement, 86, 114-124, 2016.

Soltani, M., Takaver, A., and Alimardani, R.: Moisture content determination of oilseeds based on dielectric measurement, Agric. Eng. Int. CIGR J., 16, 313-318, 2014.

Stevan Jr., S. L., Paiter, L., Galvao, J. R., Vieira Roque, D., and Sidinei Chaves, E.: Sensor and methodology for dielectric analysis of vegetable oils submitted to thermal stress, Sensors, 15, 26457-26477, 2015.

Stewart, G. N.: The changes produced by the growth of bacteria in the molecular concentration and electrical conductivity of culture media, J. Exp. Med., 4, 235-243, 1899.

Tolba, M., Ahmed, M. U., Tlili, C., Eichenseher, F., Loessner, M. J., and Zourob, M.: A bacteriophage endolysin-based electrochemical impedance biosensor for the rapid detection of Listeria cells, Analyst, 137, 5749-5756, 2012.

Ur, A. and Brown, D. F.: Monitoring of bacterial activity by impedance measurements, Chapter 5, in: New approaches to the identification of microorganisms, edited by: Heden, C. and Illeni, T., John Wiley \& Sons., New York, 63-71, 1975. 
Uria, N., Moral-Vico, J., Abramova, N., Bratov, A., and Munoz, F. $\mathrm{X}$.: Fast determination of viable bacterial cells in milk samples using impedimetric sensor and a novel calibration method, Electrochim. Acta, 198, 249-258, 2016.

Urquidi-Macdonald, M., Real, S., and Macdonald, D. D.: Applications of Kramers-Kronig transforms in the analysis of electrochemical impedance data - III: Stability and linearity, Electrochim. Acta, 35, 1559-1566, 1990.

Utter, A. C., Nieman, D. C., Ward, A. N., and Butterworth, D. E.: Use of the leg-to-leg bioelectrical impedance method in assessing body-composition change in obese women, Am. J. Clin. Nutr., 69, 603-607, 1999.

Valli, E., Bendini, A., Berardinelli, A., Ragni, L., Riccò, B., Grossi, M., and Gallina Toschi, T.: Rapid and innovative instrumental approaches for quality and authenticity of olive oils, Eur. J. Lipid Sci. Technol., 118, 1601-1619, 2016.

van Grinsven, B., Vandenryt, T., Duchateau, S., Gaulke, A., Grieten, L., Thoelen, R., Ingebrandt, S., De Ceuninck, W., and Wagner, P.: Customized impedance spectroscopy device as possible sensor platform for biosensor applications, Phys. Status Solidi A, 4, 919-923, 2010.

Vozary, E. and Benko, P.: Non-destructive determination of impedance spectrum of fruit flesh under the skin, J. Phys. Conf. Ser., 224, 1-4, 2010.

Wang, X., Zhao, Z., Wang, Y., and Lin, J.: A Portable Impedance Detector for Interdigitated Array Microelectrode for Rapid Detection of Avian Influenza Virus, IFIP Adv. Inf. Comm. Te., 8, 247-256, 2015.

Wang, Y., Ye, Z., and Ying, Y.: New Trends in Impedimetric Biosensors for the Detection of Foodborne Pathogenic Bacteria, Sensors, 12, 3449-3471, 2012.

Xie, X., Kolthoff, N., Barenholt, O., and Nielsen, S.: Validation of a leg-to-leg bioimpedance analysis system in assessing body composition in postmenopausal women, Int. J. Obes., 23, 1079-1084, 1999.

Yang, J., Zhao, K. S., and He, Y. J.: Quality evaluation of frying oil deterioration by dielectric spectroscopy, J. Food Eng., 180, 69-76, 2016.

Yang, L., Li, Y., and Erf, G. F.: Interdigitated Array MicroelectrodeBased Electrochemical Impedance Immunosensor for Detection of Escherichia coli O157:H7, Anal. Chem., 76, 1107-1113, 2004.

Yang, Y., Wang, J., Yu, G., Niu, F., and He, P.: Design and preliminary evaluation of a portable device for the measurement of bioimpedance spectroscopy, Physiol. Meas., 27, 1293-1310, 2006.
Yang, Y., Wang, Z. Y., Ding, Q., Huang, L., Wang, C., and Zhu, D. Z.: Moisture content prediction of porcine meat by bioelectrical impedance spectroscopy, Math. Comput. Model., 58, 819-825, 2013.

Yang, Y., Li, Q., Yu, X., Chen, X., and Wang, Y.: A novel method for determining peroxide value of edible oils using electrical conductivity, Food Control, 39, 198-203, 2014.

Yoneda, M., Tasaki, H., Tsuchiya, N., Nakajima, H., Hamaguchi, T., Oku, S., and Shiga, T.: A Study of Bioelectrical Impedance Analysis Methods for Practical Visceral Fat Estimation, IEEE Int. Conf. Granular Comput., Fremont, CA, USA, 2-4 November 2007, 622-627, 2007.

Yoo, J.-S. and Park, S.-M.: An electrochemical impedance measurement technique employing Fourier transform, Anal. Chem., 72, 2035-2041, 2000.

Yuan, X., Wang, H., Colin Sun, J., and Zhang, J.: AC impedance technique in PEM fuel cell diagnosis - a review, Int. J. Hydrogen Energy, 32, 4365-4380, 2007.

Zhang, M. I. N., Stout, D. G., and Willison, J. H. M.: Electrical impedance analysis in plant tissue: symplastic resistance and membrane capacitance in the Hayden model, J. Exp. Bot., 41, 371-380, 1990.

Zhang, M. I. N. and Willison, J. H. M.: Electrical impedance analysis in plant tissue: a double shell model, J. Exp. Bot., 42, 14651475, 1991.

Zhang, T., Zhou, L., Ammari, H., and Seo, J. K.: Electrical impedance spectroscopy-based defect sensing technique in estimating cracks, Sensors, 15, 10909-10922, 2015.

Zhang, X., Wang, F., and Du, Y.: Protective performance of epoxy resin modified with coal tar coating studied by electrochemical impedance spectroscopy, Prog. Org. Coat., 53, 302-305, 2005.

Zhao, X., Wang, J., Wang, Y., Kong, T., Zhong, L., and Zhang, W.: Analysis of deterioration process of organic protective coating using EIS assisted by SOM network, Electrochem. Commun., 9, 1394-1399, 2007.

Zhou, X. and King, V. M.: An impedimetric method for rapid screening of cosmetic preservatives, J. Ind. Microbiol., 15, 103107, 1995.

Zhu, H., Luo, H., Ai, D., and Wang, C.: Mechanical impedance based technique for steel structural corrosion damage detection, Measurement, 88, 353-359, 2016.

Zuo, Y., Pang, R., Li, W., Xiong, J. P., and Tang, Y. M.: The evaluation of coating performance by the variations of phase angles in middle and high frequency domains of EIS, Corros. Sci., 50, 3322-3328, 2008. 